\title{
Combining ground-based microwave radiometer and the AROME convective scale model through 1DVAR retrievals in complex terrain: an Alpine valley case study
}

\author{
Pauline Martinet ${ }^{1}$, Domenico Cimini ${ }^{2}$, Francesco De Angelis ${ }^{3}$, Guylaine Canut ${ }^{1}$, Vinciane Unger $^{1}$, Remi Guillot $^{1}$, \\ Diane Tzanos ${ }^{1}$, and Alexandre Paci ${ }^{1}$ \\ ${ }^{1}$ CNRM UMR 3589, Meteo France/CNRS, Toulouse, France \\ ${ }^{2}$ IMAA-CNR, Potenza, Italy \\ ${ }^{3}$ CETEMPS, University of L'Aquila, L'Aquila, Italy
}

Correspondence to: Pauline Martinet (pauline.martinet@meteo.fr)

Received: 4 May 2017 - Discussion started: 6 June 2017

Revised: 7 August 2017 - Accepted: 11 August 2017 - Published: 18 September 2017

\begin{abstract}
A RPG-HATPRO ground-based microwave radiometer (MWR) was operated in a deep Alpine valley during the Passy-2015 field campaign. This experiment aims to investigate how stable boundary layers during wintertime conditions drive the accumulation of pollutants. In order to understand the atmospheric processes in the valley, MWRs continuously provide vertical profiles of temperature and humidity at a high time frequency, providing valuable information to follow the evolution of the boundary layer. A one-dimensional variational (1DVAR) retrieval technique has been implemented during the field campaign to optimally combine an MWR and $1 \mathrm{~h}$ forecasts from the French convective scale model AROME. Retrievals were compared to radiosonde data launched at least every $3 \mathrm{~h}$ during two intensive observation periods (IOPs). An analysis of the AROME forecast errors during the IOPs has shown a large underestimation of the surface cooling during the strongest stable episode. MWR brightness temperatures were monitored against simulations from the radiative transfer model ARTS2 (Atmospheric Radiative Transfer Simulator) and radiosonde launched during the field campaign. Large errors were observed for most transparent channels (i.e., $51-52 \mathrm{GHz}$ ) affected by absorption model and calibration uncertainties while a good agreement was found for opaque channels (i.e., $54-58 \mathrm{GHz}$ ). Based on this monitoring, a bias correction of raw brightness temperature measurements was applied before the 1DVAR retrievals. 1DVAR retrievals were found to significantly improve the AROME forecasts up to $3 \mathrm{~km}$ but
\end{abstract}

mainly below $1 \mathrm{~km}$ and to outperform usual statistical regressions above $1 \mathrm{~km}$. With the present implementation, a root-mean-square error (RMSE) of $1 \mathrm{~K}$ through all the atmospheric profile was obtained with values within $0.5 \mathrm{~K}$ below $500 \mathrm{~m}$ in clear-sky conditions. The use of lower elevation angles (up to $5^{\circ}$ ) in the MWR scanning and the bias correction were found to improve the retrievals below $1000 \mathrm{~m}$. MWR retrievals were found to catch deep near-surface temperature inversions very well. Larger errors were observed in cloudy conditions due to the difficulty of ground-based MWRs to resolve high level inversions that are still challenging. Finally, 1DVAR retrievals were optimized for the analysis of the IOPs by using radiosondes as backgrounds in the 1DVAR algorithm instead of the AROME forecasts. A significant improvement of the retrievals in cloudy conditions and below $1000 \mathrm{~m}$ in clear-sky conditions was observed. From this study, we can conclude that MWRs are expected to bring valuable information into numerical weather prediction models up to $3 \mathrm{~km}$ in altitude both in clear-sky and cloudy-sky conditions with the maximum improvement found around $500 \mathrm{~m}$. With an accuracy between 0.5 and $1 \mathrm{~K}$ in RMSE, our study has also proven that MWRs are capable of resolving deep near-surface temperature inversions observed in complex terrain during highly stable boundary layer conditions. 


\section{Introduction}

Atmospheric boundary layer (ABL) observations of temperature and humidity profiles at a high temporal resolution are necessary for the improvement of numerical weather prediction (NWP) and for a better understanding of small-scale phenomena. In fact, a new generation of convective scale models has been developed over the last 10 years in order to improve the forecasts of high-impact weather events like heavy convection, precipitation, fog or low clouds. In order to initialize convective scale models through data assimilation algorithms, a denser network of ABL observations is needed as it is the most important under-sampled part of the atmosphere (National Research Council United States, 2010). In parallel, a better understanding of boundary layer processes is essential to improve parameterizations used to describe the evolution of phenomena at a smaller scale than the model grid. To that end, observations enabling a fine description of the diurnal evolution in the ABL are important to improve our knowledge and understanding of these smallscale phenomena. Among them, ABL processes in mountainous regions are an active area of research due to complex atmospheric dynamics, anabatic and katabatic winds and strong temperature inversions (Rotach and Zardi, 2007). Urban valleys are often affected by severe pollution events during wintertime anticyclonic conditions while the atmospheric circulation in the valley is decoupled from the synoptic dynamics aloft (Lehner and Gohm, 2010; Gohm et al., 2009; De Franceschi and Zardi, 2009; Silcox et al., 2012). This is particularly the case in the Arve River valley near the city of Chamonix, located in the French Alps where the air quality is some of the worst in France. The Passy-2015 field campaign was conducted to improve our knowledge on how pollutants are accumulated and dispersed during stable episodes in this urbanized valley (Paci et al., 2016). To better understand and forecast these pollution events, vertical profiles of temperature at a high temporal resolution can be valuable. In fact, information on the link between the atmospheric stability and the amount of pollutant in the atmosphere, as well as the description of temperature inversions and stratifications, can be studied (Silcox et al., 2012; Chemel et al., 2016).

Radiosounding remains one of the most accurate methods to measure temperature profiles but the cost and induced finite time resolution (once or twice per day usually for instrumented site) is a limitation to a fine description of the boundary layer's diurnal cycle. In contrast, ground-based microwave radiometers (MWRs) can provide continuous observations of temperature and humidity profiles at a high frequency rate (up to $1 \mathrm{~s}$ for humidity profiles, a few minutes for temperature). Even if the vertical resolution decreases with altitude (Cimini et al., 2006), information from MWRs mostly resides in the ABL (Löhnert and Maier, 2012) and atmospheric profiles are provided in both clear- and cloudysky conditions, making them useful for a long-term mon- itoring of boundary layer dynamics. Atmospheric profiles are generally retrieved from statistical regressions using a long-term database of radiosoundings (Crewell and Lohnert, 2007; Löhnert and Maier, 2012). This method relies on a long time series of radiosonde (RS) profiles to represent most of the atmospheric variability. However, such a large number of RS profiles is rarely available. NWP models can provide a database of atmospheric profiles when no RS is available (Güldner, 2013). However, this method may not be well suited in complex terrain for which forecast skills are known to be less accurate, particularly due to unrepresented processes associated with subgrid-scale orography. One-dimensional variational (1DVAR) retrievals have also been used to retrieve in an optimal way temperature and humidity profiles by combining observations and an a priori estimate of the atmospheric state. This a priori profile can be represented by a climatological profile based on radiosounding at an instrumented site (Löhnert et al., 2004, 2008) or a short-term forecast from a NWP model. The 1DVAR technique was applied by Hewison (2006), Cimini et al. (2006), Hewison (2007), Cimini et al. (2010) and Cimini et al. (2011) using forecasts from a mesoscale model on various datasets of MWR observations from the MeteoSwiss station of Payerne to observations in Alaska or Vancouver during the 2010 Olympic Games. A root-mean-square error (RMSE) within $1.5 \mathrm{~K}$ was obtained for the three experiments by comparison to radiosondes. Recently, Martinet et al. (2015) illustrated for the first time a 1DVAR assimilation of real MWR observations into the convective scale model AROME (Application of Research to Operations at MEsoscale; Seity et al., 2011) and obtained an RMSE within $1 \mathrm{~K}$ in clear sky and $1.3 \mathrm{~K}$ in cloudy sky, up to $6 \mathrm{~km}$, with most of the information content brought into the model being located below $3 \mathrm{~km}$ altitude.

During the Passy-2015 field campaign, a 14-channel MWR has been operated from December 2014 to March 2015 in a deep and narrow Alpine valley. Although there have already been MWR deployments on complex terrain (Kneifel et al., 2010; Cimini et al., 2011; Massaro et al., 2015), this study investigates the following questions:

- Can ground-based MWRs resolve temperature profiles characterized by sharp temperature inversions during very stable conditions in such a deep and narrow valley?

- What added value can MWRs bring to NWP models in stable conditions which are known to be a current issue in NWP forecasts?

To that end, a MWR has been deployed in a narrow Alpine valley (less than $5 \mathrm{~km}$ between the closest mountain slope and the instrument) with measurements going down to $5^{\circ}$ elevation angle. This is the first time 1DVAR retrievals are performed from a convective scale model in complex terrain during which large forecast errors are observed. 
The paper begins with an overview of the instrumentation used in the Passy-2015 field campaign (Sect. 2) and the 1DVAR algorithm (Sect. 3) followed by an analysis of the AROME forecast errors during the experiment (Sect. 4). Monitoring of the radiometer brightness temperature (BT) measurements enabling the computation of a bias correction is presented in Sect. 5. Finally, performance of 1DVAR retrievals compared to regressions is discussed in Sect. 6.

\section{Instrumentation}

\subsection{The Passy-2015 field campaign}

The Passy-2015 field campaign was designed in order to improve our understanding of how the atmospheric dynamics during wintertime anticyclonic conditions, leading to persistent stable boundary layers, drives the accumulation and dispersion of pollutants in the atmosphere of the Arve valley around the city of Passy. This French urbanized valley is known for severe pollution episodes with daily concentration of PM10 (aerosols with diameter less than $10 \mu \mathrm{m}$ ) regularly above $50 \mathrm{\mu gm}^{-3}$. The valley is approximately $2000 \mathrm{~m}$ deep and maximum $2 \mathrm{~km}$ wide (Fig. 1). The ground altitude is approximately $560 \mathrm{~m}$ a.g.l in the valley. A large number of instruments were deployed from the end of November 2014 to the end of March 2015 on five instrumented sites in the valley. Among them are microwave radiometers, wind profilers, ceilometer, sodar, lidars, tethered balloons and instrumented towers. A detailed presentation of the field campaign can be found in Paci et al. (2016). Two intensive observation periods (IOPs) have been carried out during the campaign. The observing system was reinforced during these periods with radiosondes launched every $3 \mathrm{~h}$ and up to $1.5 \mathrm{~h}$. The first IOP took place from 6 to 14 February and the second one from 17 to 20 February.

\subsection{HATPRO MWR}

A HATPRO MWR (Rose et al., 2005) was deployed on site 1 (Fig. 1) and is oriented to scan the Passy valley in two opposite directions: Passy in the northeastern and Sallanches in the northwestern direction. The HATPRO MWR measures downwelling BTs in 14 channels. The first seven are located on the upper-frequency wing of the $22.24 \mathrm{GHz}$ water vapor absorption line (called K-band), and the last seven are at the $60 \mathrm{GHz}$ oxygen complex band (called V-band). K-band channels are used to retrieve atmospheric humidity and liquid water content while V-band channels are used for atmospheric temperature retrievals. Observations are made either in zenith mode pointing at $90^{\circ}$ or in boundary layer mode scanning the atmosphere under lower elevation angles from 90 to $5.4^{\circ}$. One boundary layer scan is performed in each direction approximately every $10 \mathrm{~min}$. The use of a boundary layer scan was found to significantly improve the accuracy of temperature profiles in the first kilometers, assuming that the

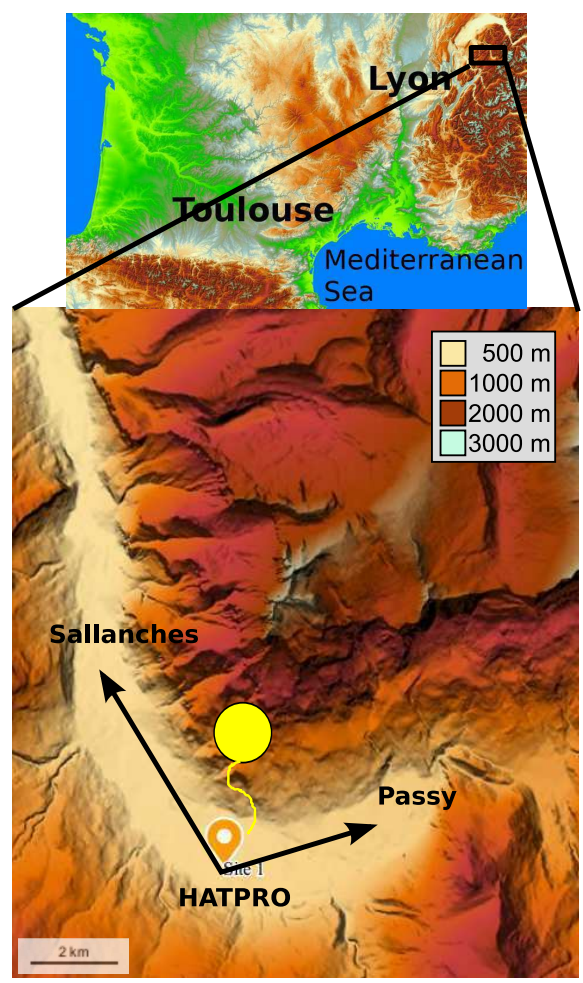

Figure 1. View of the area of interest, close to the city of Passy in the Arve River valley. Microwave radiometer and radiosondes were deployed at measurement site 1. Topographic maps from www.geoportail.gouv.fr (IGN 2017).

atmosphere is horizontally homogeneous around the MWR (Crewell and Lohnert, 2007). Even if this assumption is not necessarily valid in complex terrain, the study of Massaro et al. (2015) has shown a good accuracy of temperature profiles with no degradation due to the nearby mountain. The radiometer needs to be well calibrated to exploit the optimal calibration coefficients in order to convert detected intensities into BTs. To that end a liquid nitrogen cooled load considered as a blackbody at the boiling temperature of $77 \mathrm{~K}$ is generally used (Küchler et al., 2016). A liquid nitrogen calibration was performed at the beginning of the experimental campaign at the end of November 2014.

\subsection{Ancillary data}

In addition to the HATPRO MWR, observations by 84 RS ascents are used to validate temperature profiles retrieved by the MWR. VAISALA RS92 radiosondes with an expected accuracy of $0.5 \mathrm{~K}$ in temperature and $5 \%$ in relative humidity were launched approximately every $3 \mathrm{~h}$ and up to $1.5 \mathrm{~h}$ during the IOPs. Radiosondes were launched at approximately 00:00, 03:00, 06:00, 09:00, 12:00, 15:00, 18:00 and 21:00 UTC. They provide vertical profiles of pressure, temperature, relative humidity and wind profiles at approximately $10 \mathrm{~m}$ vertical resolution. The temperature at $1.5 \mathrm{~m}$ is 
provided by an external weather station combined with the RS measurements through the VAISALA software. A new system to increase the frequency of radiosondes by recovering previously launched probes has been used during the field campaign (Legain et al., 2013). In order to be able to pick up the probes, they should not drift too far away from the launching site. As a consequence, most of the radiosondes were released at about $2 \mathrm{~km}$ altitude to make sure they could be picked up in the valley. A ceilometer Vaisala CT25K deployed a few meters from the MWR is also used to determine the cloud base altitude. This cloud base can be used to optimize the 1DVAR retrievals in cloudy conditions and to separate clear-sky from cloudy-sky observations when analyzing the results.

\section{Retrieval algorithm}

\subsection{DVAR framework}

A comparison of several methods to convert BTs into temperature and humidity profiles have proven the 1DVAR technique to be the optimal one (Cimini et al., 2006; Martinet et al., 2015) when the a priori profile and uncertainty estimates are suitable. The 1DVAR framework used in this study is based on the optimal estimation theory by Rodgers (2000). MWR observations are combined with an a priori estimation of the atmospheric state, which can be either a shortterm forecast or a previous RS profile. In this context, a priori refers to the first guess of the iterative algorithm, representing a good estimate of the atmospheric conditions as the starting point of the minimization. Each source of information is weighted by corresponding uncertainty called the background-error-covariance matrix (B) for the a priori profile and the observation-error-covariance matrix $(\mathbf{R})$ for the observation to find the optimal state. The backgrounderror-covariance matrix represents the auto-covariances and cross-covariances of the first-guess errors. Thus, it defines the variances of the first-guess errors at each vertical level for each variable, the vertical correlations of the first-guess errors at different levels and the correlation of these errors between different variables (temperature and humidity, for example). An observation operator, including interpolations from model space to observation space and a radiative transfer model, is needed to compute the equivalent observation from the a priori. The method iteratively modifies the state vector $\boldsymbol{x}$ from the a priori $\boldsymbol{x}_{b}$ to minimize the following cost function:

$$
\begin{gathered}
J(\boldsymbol{x})=\frac{1}{2}\left(\boldsymbol{x}-\boldsymbol{x}_{b}\right)^{T} \mathbf{B}^{-1}\left(\boldsymbol{x}-\boldsymbol{x}_{b}\right)+\frac{1}{2}(\boldsymbol{y}-\mathbf{H}(\boldsymbol{x}))^{T} \\
\mathbf{R}^{-1}(\boldsymbol{y}-\mathbf{H}(\boldsymbol{x}))
\end{gathered}
$$

where $\mathbf{H}$ represents the observation operator, ${ }^{T}$ represents the transpose operator and ${ }^{-1}$ is the inverse operator. The observation-error-covariance matrix $\mathbf{R}$ should take into account representativeness and forward model errors as well as radiometric noise.

During the minimization process, a Levenberg-Marquardt descent algorithm is applied by introducing a factor $\gamma$ that is adjusted after each iteration. If the cost function is not decreased with the new profile, the factor $\gamma$ is multiplied by 10 . The iterative solution that minimizes the cost function $J$ is given by

$$
\begin{array}{r}
\boldsymbol{x}_{i+1}=\boldsymbol{x}_{i}+\left((1+\gamma) \mathbf{B}^{-1}+\mathbf{H}_{i}^{T} \mathbf{R}^{-1} \mathbf{H}_{i}\right)^{-1} \times \\
\left(\mathbf{H}_{i}^{T} \mathbf{R}^{-1}\left(\boldsymbol{y}-\mathbf{H}\left(\boldsymbol{x}_{i}\right)\right)-\mathbf{B}^{-1}\left(\boldsymbol{x}_{i}-\boldsymbol{x}_{b}\right)\right),
\end{array}
$$

where $\mathbf{H}_{i}$ is the Jacobian matrix, which represents the sensitivity of the observation operator to changes in the control vector $\boldsymbol{x}\left(\mathbf{H}_{i}=\partial \mathbf{H}\left(\boldsymbol{x}_{i}\right) / \partial \boldsymbol{x}_{i}\right)$.

\subsection{NWP model}

In this study $1 \mathrm{~h}$ forecasts from the French convective scale model AROME are used as a priori profiles or "backgrounds". AROME is a limited area model covering western Europe with non-hydrostatic dynamical core. Since beginning in 2015, the horizontal resolution of AROME has been increased from 2.5 to $1.3 \mathrm{~km}$ as well as the number of vertical levels from 60 to 90 (Brousseau et al., 2016). This increase in horizontal and vertical resolutions is particularly useful to better represent complex terrains. Vertical levels follow the terrain in the lowest layers and isobars in the upper atmosphere. The detailed physics of AROME are inherited from the Meso-NH model (Lafore et al., 1997). Deep convection is assumed to be resolved explicitly, but shallow convection is parameterized following Pergaud et al. (2009). A bulk onemoment microphysical scheme (Pinty and Jabouille, 1998) governs the equations of the specific contents of six water species (humidity, cloud liquid water, precipitating liquid water, pristine ice, snow and graupel). This new version also performs 3DVAR analyses every hour instead of every $3 \mathrm{~h}$ to optimize the use of frequent observations. All conventional observations are assimilated together with wind profilers, winds from space-borne measurements (atmospheric motion vectors and scatterometers), Doppler winds (Montmerle and Faccani, 2009) and reflectivity (Wattrelot et al., 2014) from ground-based weather radars, satellite radiances and ground-based GPS measurements (Mahfouf et al., 2015).

\subsection{Settings}

In this study the control vector $\boldsymbol{x}$ consists of temperature and humidity profiles on the same 90 levels as defined in AROME. These levels cover the atmospheric range from the ground up to $30 \mathrm{~km}$, the vertical resolution decreasing with altitude: $20-100 \mathrm{~m}$ below $1 \mathrm{~km}, 100-200 \mathrm{~m}$ from 1 to $5 \mathrm{~km}$ around $400 \mathrm{~m}$ at $10 \mathrm{~km}$. It is important to note here that the 
retrieval grid is finer than the true instrumental resolution but matches the AROME model vertical resolution. The observation vector $\boldsymbol{y}$ consists of BT in all V-band channels (51.26, $52.28,53.86,54.94,56.66,57.3,58 \mathrm{GHz}$ ) at zenith and only opaque channels (above $54 \mathrm{GHz}$ ) at low elevation angles: 42 , $30,19.2,10.2$ and $5.4^{\circ}$. This study only focusses on temperature profiles, and thus only V-band channels are used. The forward model operator used in this study is the line-by-line Atmospheric Radiative Transfer Simulator 2 (ARTS2; Eriksson et al., 2011) and 1DVAR experiments are performed using the Qpack2 package (Eriksson et al., 2005) provided with the ARTS2 software. For the radiative transfer simulations, the gaseous absorption is calculated according to Rosenkranz (1998) for $\mathrm{O}_{2}$ and water vapor. In simulations taking into account the liquid water absorption, the model of Liebe et al. (1993) is used.

The observation-error-covariance matrix $\mathbf{R}$ is assumed to be uncorrelated with a standard deviation of $0.5 \mathrm{~K}$ for channels 8 to 9 and $0.2 \mathrm{~K}$ for channels 10 to 14 . These values have been chosen empirically on the basis of previous studies by Löhnert et al. (2008) and Hewison (2007). The same values have been used in Martinet et al. (2015) with the instrument used in this study and have shown to be good estimates of the observation errors. In the future, a dedicated study will be performed to review these values and quantify the correlations in noise between the different channels by continuously measuring the BTs of the internal blackbody target.

Information about instrumental errors can be obtained by investigating differences between observations and simulations from background profiles (short-term forecasts or radiosondes). The monitoring of these differences, called O-B (observations minus background) departures, is essential to remove any systematic errors in the measurements, the forward operator or the background profiles (De Angelis et al., 2017). They are investigated in Sect. 5.

\section{Evaluation of the AROME model during the Passy-2015 field campaign}

In real time during the Passy-2015 field campaign, temperature profiles were retrieved from the MWR measurements using linear regressions implemented within the HATPRO proprietary software. The regression coefficients were provided by the RPG manufacturer to the national service MeteoSwiss and are based on the 1989-2005 Payerne RS data via radiative transfer calculations. The Payerne coefficients were chosen due to the lack of RS data close to the city of Passy and for the similar climatic conditions between Passy and Payerne.

In order to evaluate the performance of the AROME model during the Passy-2015 experiment, Fig. 2 shows the time series of temperature profiles observed by radiosondes, retrieved from the HATPRO MWR by the Payerne linear regression coefficients and extracted from the AROME analy- ses during the first IOP. The stable episode starts 9 February and ends 13 February. During this event a persistent inversion is observed, but we note that stability is depleted in the first $500 \mathrm{~m}$ every day between noon and 15:00 to 17:00 due to the solar heating. The diurnal cycle and a very cold air mass (up to $-10^{\circ} \mathrm{C}$ ) close to the surface at night are very well detected by the MWR. We observe a good agreement of the overall atmospheric structure between RS data and MWR observations. The RMSE between the regressions and the radiosondes are $0.7 \mathrm{~K}$ below $500 \mathrm{~m}$ except the first two points close to the surface, which are below $1.3 \mathrm{~K}$ at $1200 \mathrm{~m}$ and increase up to $2 \mathrm{~K}$ at $4000 \mathrm{~m}$. These values are consistent with those reported in Löhnert and Maier (2012) from another HATPRO radiometer operated in a less complex terrain and from Massaro et al. (2015) in a truly complex terrain in the Inn Valley. This result confirms that microwave radiation that could originate from nearby slopes does not seem to degrade the quality of MWR inversions. MWRs can thus be safely deployed in complex terrain and then similar temperature accuracy to that of flat and less complex terrain can be expected, at least if the line of sight of the MWR is free of obstacles over distances larger than about $5 \mathrm{~km}$.

Figure 2 also demonstrates that the $10 \mathrm{~min}$ resolution of the MWR observations during the field campaign is a real advantage to complete the RS time series for a detailed description of the boundary layer diurnal cycle. During IOP 1 , the 2015 operational version of the AROME model missed the large cooling of the surface at nighttimes. The AROME model demonstrated difficulties in properly representing such conditions, which is a well-known issue of current NWP models. It induces large differences between the RS observations and the AROME forecasts by up to $-12 \mathrm{~K}$ at the surface during the strongest stable event (10, 11 and 12 February).

To quantify the accuracy of the AROME analyses in the valley during IOP 1, Fig. 3 shows temperature differences between RS and AROME at three different levels: 1.5, 1000 and $1500 \mathrm{~m}$ a.g.l. The measurement at $1.5 \mathrm{~m}$ comes from a wellventilated external weather station. To interpret these temperature errors, the difference between the RS temperature measurement at the boundary layer height $z i$ and the surface measurement from the external weather station is calculated: $\Delta T=T_{\mathrm{RS}}(z i)-T_{\text {station }}(1.5 \mathrm{~m})$. To estimate the thin convective layer top during the day that develops under the effect of solar heating, we used one of the standard definitions given by Stull (2012) and Sullivan et al. (1998) as the height of the maximum gradient of potential temperature. The estimation of the boundary layer height in stable conditions is more tricky and has been a longstanding problem, with definitions varying according to the application. Here, the stable boundary layer top has been defined as the top of the surface inversion of the stable layer using the definition from Beyrich (1997). This definition is used when a positive temperature gradient near the surface is found. The temperature difference $\Delta T$ quantifies the ABL stability. Negative values 

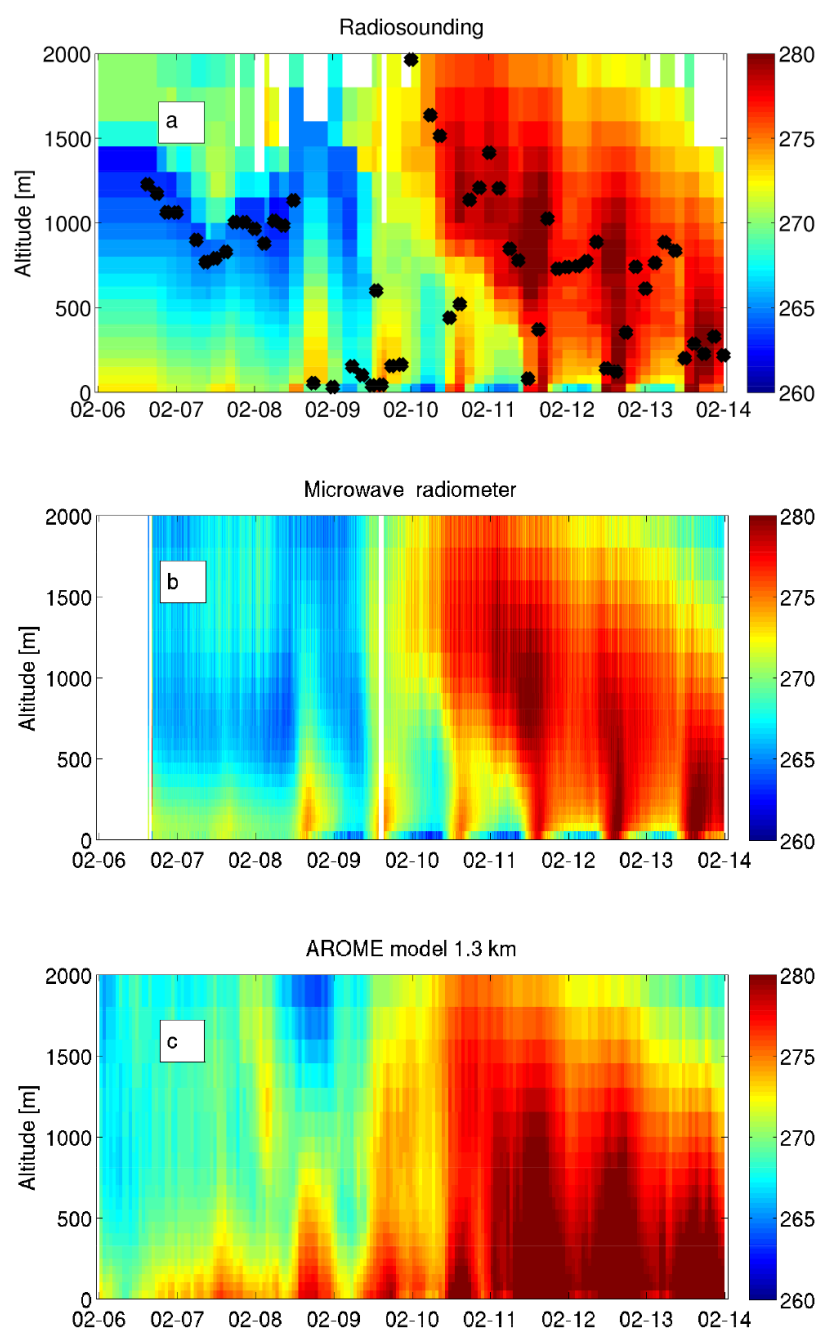

Figure 2. Time series of temperature profiles during IOP 1: (a) from radiosounding with corresponding boundary layer heights (black crosses); (b) from microwave radiometer; (c) from AROME analyses. Altitudes are given in meters above ground level.

indicate convective conditions while positive values indicate stable conditions that are more pronounced when the temperature difference is larger. The term "stability index" will be used in our analysis. We can note that the surface error is relatively low at the beginning of the period (smaller than $5 \mathrm{~K})$ and increases with the atmospheric stability. The stability index increases from 9 to 11 February and decreases after to reach values similar to the beginning of the episode. The stability index changes from positive (i.e., stable) to negative (i.e., unstable) every day between 12 and 18:00 UTC approximately. The temperature errors of the AROME analyses at the surface are consistent with the evolution of the atmospheric stability. The largest errors reach $-12 \mathrm{~K}$ on 11 February at 03:00 UTC (Fig. 4) when the stability is maximal with a value of $14 \mathrm{~K}$.
In contrast, the evolution of the $1000 \mathrm{~m}$ temperature error is not correlated with the atmospheric stability and shows larger errors before the stable conditions ( 9 February), with a stability index reaching $-10 \mathrm{~K}$. At the beginning of the IOP, cloudy conditions with low-level clouds located around $1000 \mathrm{~m}$ were observed. This resulted in a sharp temperature inversion at the cloud base (Fig. 4), which is also a known source of error in NWP forecasts. At $1500 \mathrm{~m}$ a.g.l, the error stays within $2 \mathrm{~K}$ during all the period showing a good accuracy of the AROME analyses at an altitude corresponding roughly to the averaged valley crest.

To summarize, the accuracy of the AROME analyses is degraded inside the valley, which is affected by an atmospheric circulation decoupled from the synoptic dynamics above the valley crest. The degradation of the AROME analyses is correlated with the establishment of the stable episode. The surface cooling is strongly underestimated by AROME in this context. However, above the top of the valley, the analysis errors are much smaller and correspond to the expected accuracy of the model. This result confirms the fact that MWRs can bring valuable information in the altitude range where the NWP error is the largest and where a lack of observations is still observed in operational networks.

\section{Observation minus background monitoring}

\subsection{Data screening}

In order to remove discrepancies in the forward simulations due to cloud mislocations in the forecast model, a screening of MWR observations between clear- and cloudy-sky cases has been performed. First of all, a sanity check is performed to remove MWR observations for which the rain flag provided within the instrument data stream was activated. As the HATPRO configuration was optimized to retrieve temperature profiles at a high vertical resolution, few zenithal observations were performed between two boundary layer scans. Note that the small amount of data at zenith does not allow the use of the standard deviation of MWR BT measurements at $31 \mathrm{GHz}$ to detect possible clouds in the field of view of the instruments (Ebell et al., 2017). The cloud base height provided by the CT25K ceilometer was thus used as a reference to identify cloudy-sky observations. If the lowest cloud base height during a \pm 20 min window around the MWR observation is smaller than $6000 \mathrm{~m}$, the observation is classified as cloudy. In case no ceilometer observation is available, the infrared radiometer temperature provided with the HATPRO platform has to be smaller than $-30^{\circ} \mathrm{C}$ to consider the observation as liquid free (similar approach used in Martinet et al., 2015).The result of this classification of radiosondes between clear-sky and cloudy-sky observations is shown in Fig. 5 in addition to the ceilometer cloud base height. Among the 84 radiosondes launched during the Passy-2015 field campaign, 56 were classified as clear sky. 
(a) Temperature difference RS - AROME [K]

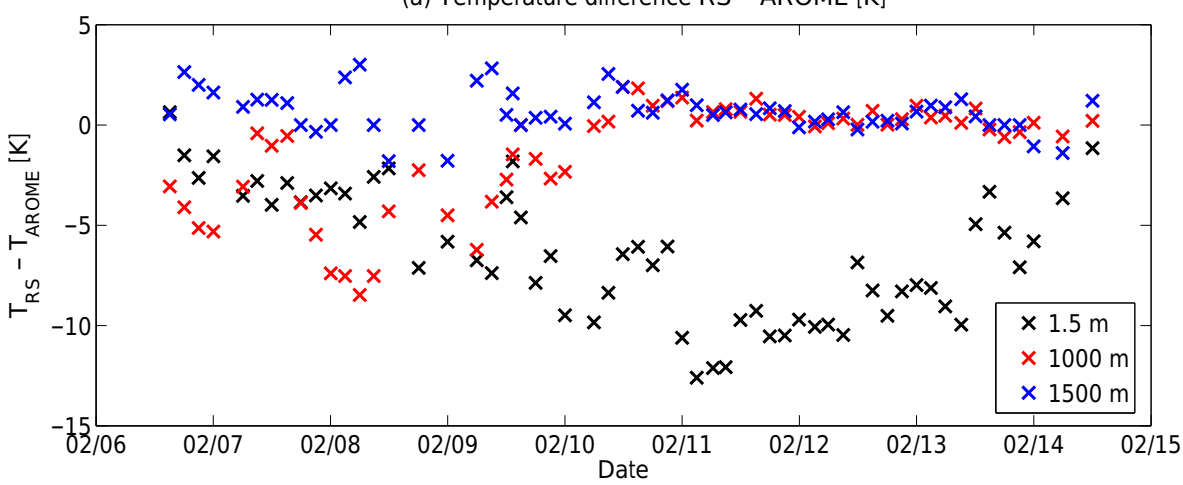

(b) Stability index

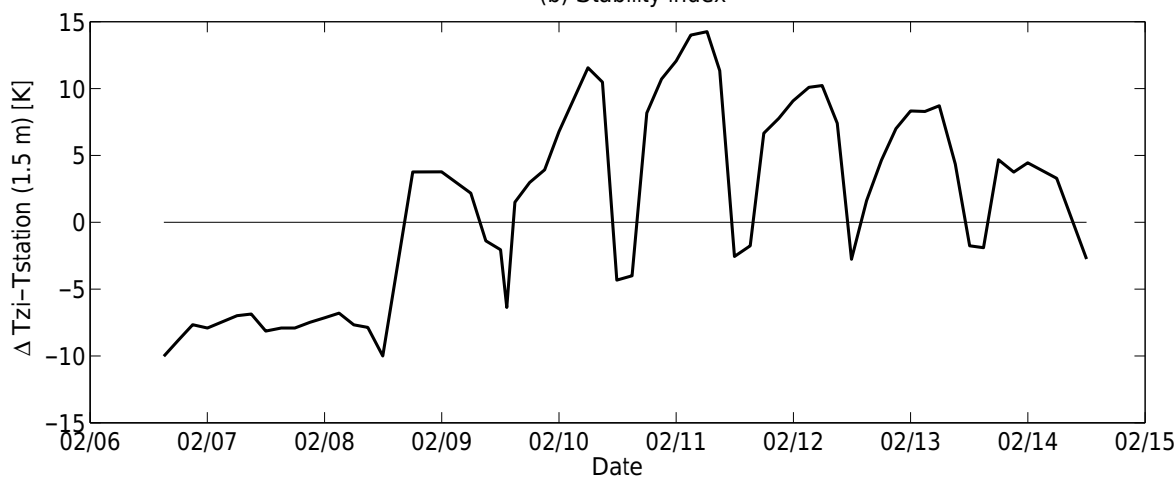

Figure 3. (a) Temperature differences between radiosondes and AROME analyses at three levels: $1.5 \mathrm{~m}$ in black, $1000 \mathrm{~m}$ in red and $1500 \mathrm{~m}$ in blue. (b) Temperature differences between the radiosonde measurement at the boundary layer height and the surface measurement from an external weather station. Altitudes are given in meters above ground level.
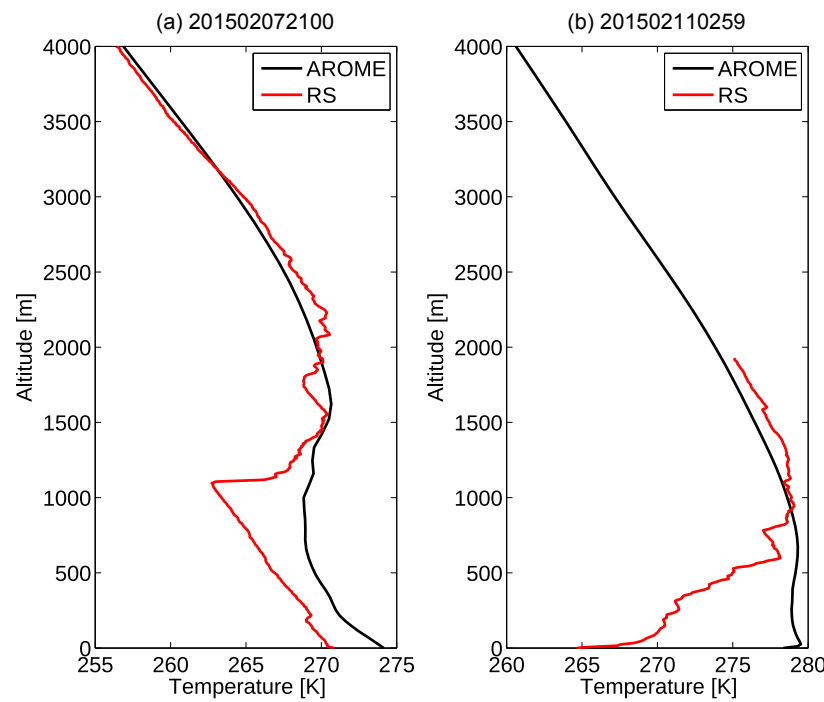

Figure 4. Temperature profiles observed by the radiosonde (red line) or extracted from the AROME analyses (black line): during unstable conditions 7 February at 21:00 UTC (a) and during the most stable period 11 February at 03:00 UTC (b). Altitudes are given in meters above ground level.

\subsection{O-B analysis from AROME forecasts}

Monitoring observation minus background departures is an important step before any assimilation. First of all, the best estimate of the analysis state is obtained only if background and observation errors follow Gaussian distribution with zero mean. Quality-controlled and bias-free observations are thus necessary to obtain a good estimate of atmospheric profiles. Should not this be the case, a bias correction of the observations can be proposed to meet the requirements of variational assimilation. While Löhnert and Maier (2012) and Navas-Guzmán et al. (2016) used RS to simulate the equivalent brightness temperature spectrum, Martinet et al. (2015) showed the possibility of using the AROME forecasts instead of RS data. Using AROME forecasts enables the detection of BT bias offset when no RS is available close to the MWR site. However, a new source of error is added, coming from possible systematic NWP errors. Even though differentiating the different sources of errors (instrumental, forward model and background errors) can be complex, this monitoring is widely used in the satellite data community.

BT simulations were performed with the ARTS2 radiative transfer model and $1 \mathrm{~h}$ AROME forecasts (temperature, humidity) using 2 months of data (February and March 2015). 


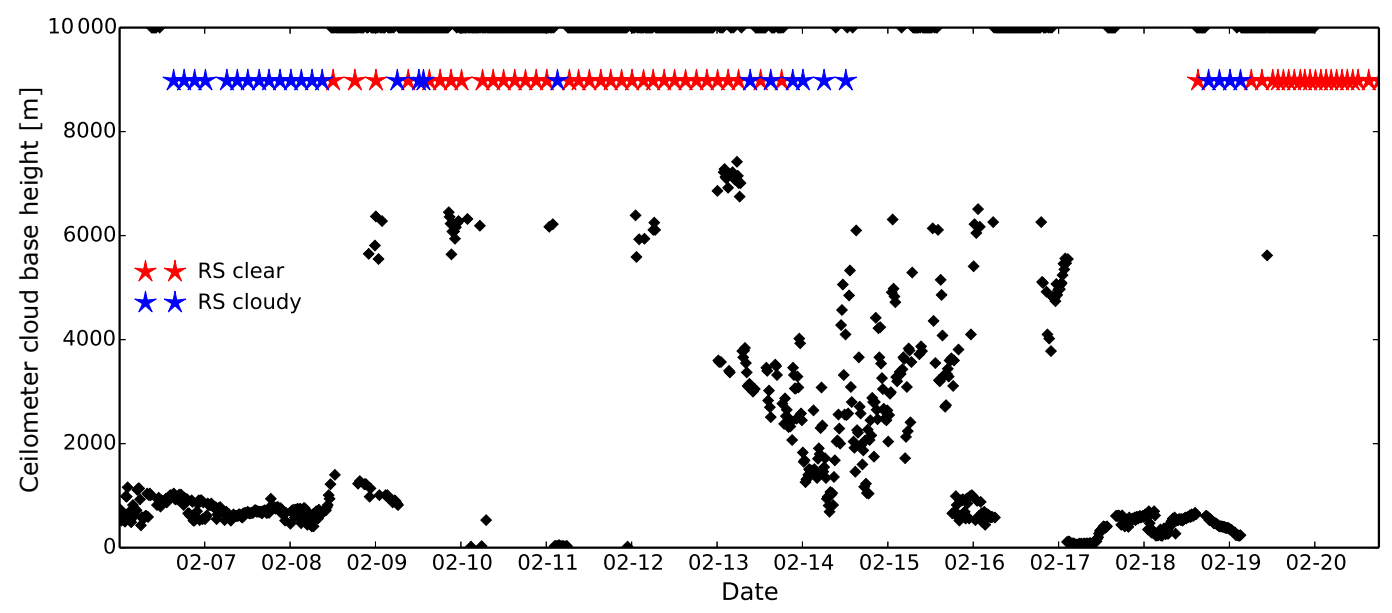

Figure 5. Cloud base height retrieved from ceilometer CT25K during the two IOPs of the Passy-2015 experiment. Stars represent the launch times of the radiosondes during the campaign classified as clear sky in red and cloud sky in blue. When no cloud was found by the ceilometer (clear sky), a value of $10000 \mathrm{~m}$ was chosen by default.

The closest AROME grid point in the valley with an altitude difference of only $2 \mathrm{~m}$ compared to the MWR location was used. Figure 6 shows the O-B departure as a function of the ABL stability for one transparent channel $(51.26 \mathrm{GHz})$ and one opaque channel $(58 \mathrm{GHz})$ and different elevation angles. Only clear-sky observations are considered with a screening procedure described in Sect. 5.1. As radiosondes are not available throughout the period, the atmospheric stability is computed from MWR temperature profiles retrieved by linear regression. The temperature difference between 500 and $50 \mathrm{~m}$ is used. Different altitudes have been tested but $500 \mathrm{~m}$ was found to best describe the development and destruction of stability in the boundary layer, at least during the IOPs. The MWR temperature retrieval at surface was not used as large errors have been observed (1.9 K; see Fig. 9) and would impact the evaluation of the stability. Instead, the second level of the MWR retrievals $(50 \mathrm{~m})$ has been chosen as it has shown a better accuracy with respect to RS measurements. From this figure, we can observe that the O-B departures at $58 \mathrm{GHz}$ are highly correlated to the atmospheric stability, which is not the case at $51.26 \mathrm{GHz}$. As opaque channels are more sensitive to the lowest atmospheric layers, this result indicates that the forward simulations are highly affected by the larger AROME forecast errors in the boundary layer during stable episodes. In contrast, the accuracy of the AROME forecasts in the upper layers stays stable during the period. The forward simulations at $51.26 \mathrm{GHz}$ are thus quite stable during the whole campaign. Larger errors are also found with decreasing elevation angles for both transparent and opaque channels. For opaque channels, this can be explained by an increased sensitivity to atmospheric layers close to the surface, where the largest errors in the AROME forecasts are observed. For transparent channels, radiations from surrounding slopes can degrade the observations and atmospheric in- homogeneities can cause larger discrepancies with the simulation.

This section has shown that, in the particular case of the Passy-2015 experiment, the use of AROME forecasts to infer any systematic BT offset is not appropriate. In fact, the large forecast errors during wintertime stable episodes exceed the instrumental errors. The computation of $\mathrm{O}-\mathrm{B}$ departures on a larger time period could probably smooth the forecast errors to only highlight instrumental errors like calibration jumps, systematic errors and drifts. In order to correctly infer any BT offset, the O-B departures are computed from the radiosondes launched during the IOPs in the next section.

\subsection{O-B analysis from radiosondes}

Observation minus background departures have been computed from RS profiles launched during the field campaign. As most of the radiosondes did not reach more than $2 \mathrm{~km}$ altitude above ground, it is important to complete the atmospheric profiles up to $30 \mathrm{~km}$ to avoid large discrepancies in the simulation of transparent channels. Radiosondes were interpolated into the AROME vertical grid below $2 \mathrm{~km}$ and completed with AROME analyses above. As the accuracy of AROME analyses is better than $1 \mathrm{~K}$ above $2 \mathrm{~km}$, this combination should not degrade the forward simulations. Figure 7 shows the bias and standard deviation of O-B departures at different elevation angles. We can note a stronger dependency to the elevation angles for transparent channels (51 to $52 \mathrm{GHz}$ ). These channels are more sensitive to calibration errors for decreasing optical depth (higher elevation angles). The largest bias $(-4.2 \mathrm{~K})$ is found at $52.25 \mathrm{GHz}$ and an elevation angle of $90^{\circ}$, while it is below $0.5 \mathrm{~K}$ for opaque channels. Standard deviations within $1 \mathrm{~K}$ are observed for all channels and all elevation angles except at $51.25 \mathrm{GHz}$ for elevation angles lower than $19.2^{\circ}$ and for angles at $52.25 \mathrm{GHz}$ 

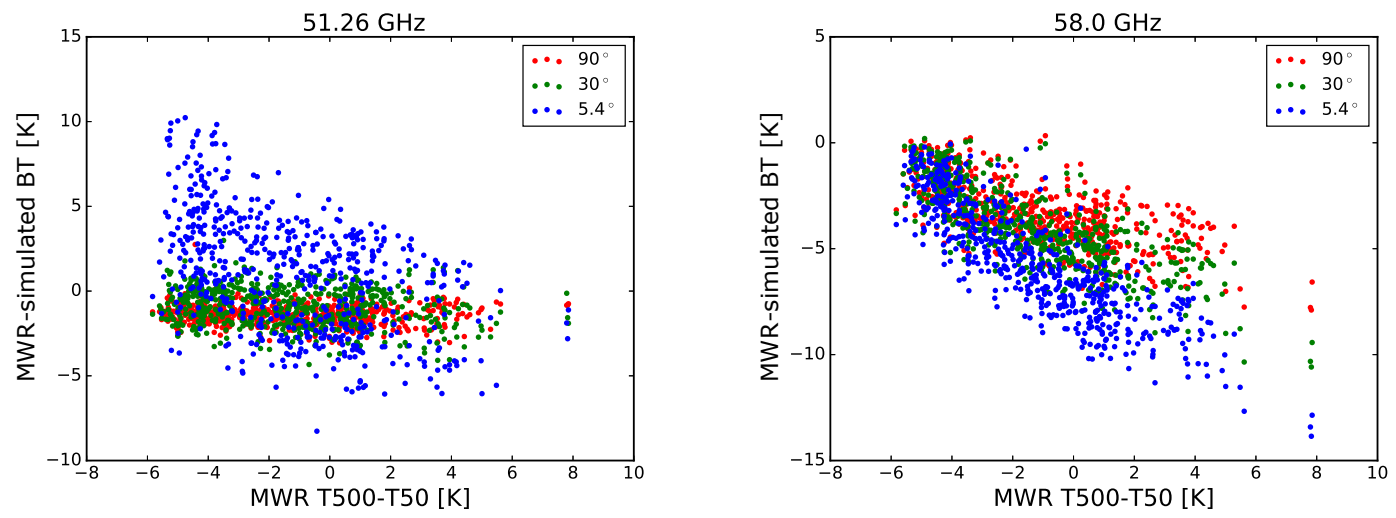

Figure 6. Observation minus background (AROME forecasts) departures as a function of HATPRO temperature differences between 500 and $50 \mathrm{~m}$ and different elevation angles from 90 to $5.4^{\circ}$.

at $5.4^{\circ}$. This degradation could be due to an increase in atmospheric inhomogeneities, indicating that transparent channels are generally not used at low elevation angles (Crewell and Lohnert, 2007). For opaque channels, bias and standard deviation smaller than $0.2 \mathrm{~K}$ are observed at all angles except $5.4^{\circ}$, where the bias reaches $0.5 \mathrm{~K}$. Similar values were found in the study of Martinet et al. (2015) with the same HATPRO instrument on a less complex terrain. The consistency between both studies points out the good stability of the instrument despite several deployments and calibrations. An improvement in the calibration procedure has also been observed with a significant decrease of standard deviation for all channels (up to 3 times at $90^{\circ}$ ). A similar bias shape was found in Löhnert and Maier (2012) and Navas-Guzmán et al. (2016), with a large negative bias at $52.25 \mathrm{GHz}$, as well as at several sites in Europe (De Angelis et al., 2017).

This large bias can be due to a combination of calibration errors and absorption model uncertainties (Hewison, 2006). This analysis demonstrates that a constant bias correction can be safely applied to the set of measurements used for temperature retrievals: only zenith angle for frequency below $53 \mathrm{GHz}$ and all elevation angles above. It will be applied and discussed in the next sections.

\section{IDVAR retrievals}

\subsection{Background errors}

In the operational AROME model, the background-errorcovariance matrix $\mathbf{B}$ is computed from an ensemble assimilation that considers explicit observation perturbations and implicit background perturbations through the cycling (Brousseau et al., 2011). The AROME ensemble assimilation is coupled to the operational ensemble assimilation at global scale, AEARP (Berre et al., 2007). However, the expected background accuracy (diagonal terms of the $\mathbf{B}$ matrix) suggests a forecast error of less than $1 \mathrm{~K}$ in the boundary layer on average through all the AROME domain. This operational $\mathbf{B}$ matrix significantly underestimates the AROME forecast errors during the Passy-2015 experiment. A new B matrix has thus been computed from the differences between the AROME forecasts and the RS data in both clear sky and cloudy skies, similarly to Cimini et al. (2011). The bias and standard deviation of these differences compared to the operational background errors used for the assimilation of satellite data are shown in Fig. 8. A large bias in temperature of approximately $-5 \mathrm{~K}$ is observed at the surface and corresponds to the large overestimation of the temperature by AROME during the stable episodes. A standard deviation of 2 to $3 \mathrm{~K}$, which is 2 to 3 times larger than the expected background error, is evident between the surface and $1700 \mathrm{~m}$. The temperature error at higher altitude is much smaller $(\sim 1 \mathrm{~K})$ and closer to the value prescribed in the operational assimilation system, corresponding to a decrease in the forecast error above the valley crest. Similar features were found with ECMWF and NCEP models in an Arctic environment in the study of Cimini et al. (2010). As the 1DVAR retrieval accuracy depends on how well the $\mathbf{B}$ matrix is defined, the diagonal terms of the $\mathbf{B}$ matrix (auto-covariance of the temperature errors) were simply replaced by the variance of the RS minus AROME differences (i.e., the square of standard deviation values in Fig. 8) below $2 \mathrm{~km}$. In order to provide statistically consistent increments at the neighboring levels of the model, the vertical correlations of the operational $\mathbf{B}$ matrix were conserved. Non-Gaussianity can also affect forecast errors. Recently, Legrand et al. (2016) evaluated the non-Gaussianity of analysis and forecast errors using a 90member AROME ensemble assimilation. It was found that for all variables, non-Gaussianity exists but dynamical variables (vorticity and divergence) are more affected than temperature and humidity. Data assimilation reduces this nonGaussianity at each cycle in regions covered well by observations. This ensemble assimilation does not exist for our period, making the evaluation of this Gaussianity in our con- 


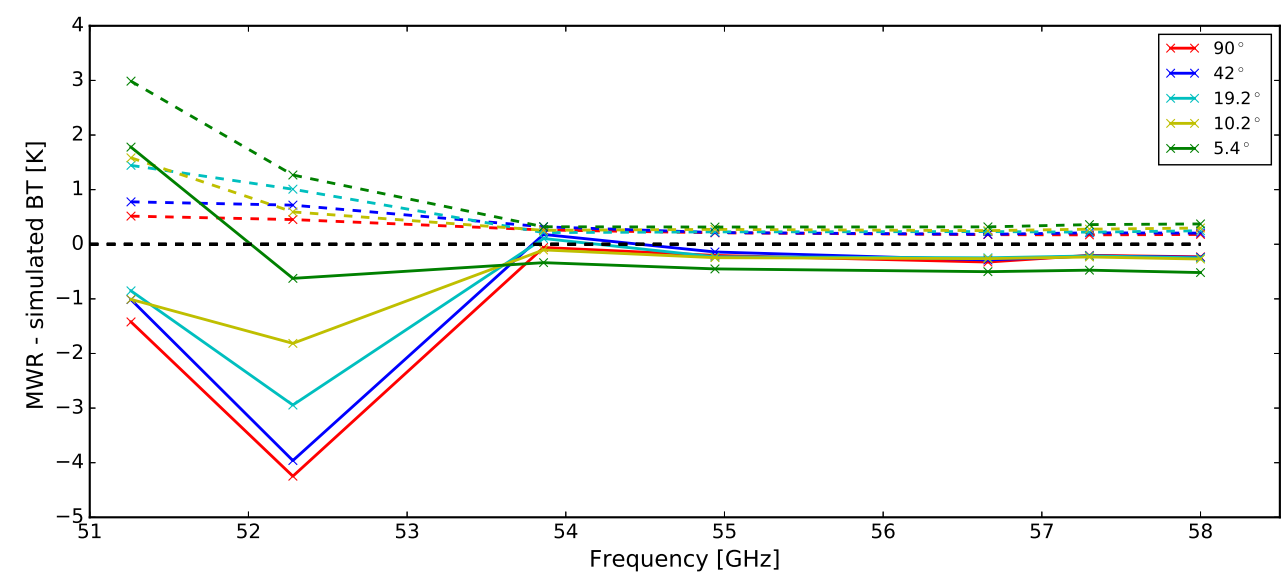

Figure 7. Observation minus background departures from radiosondes combined with AROME analyses for different elevation angles from 90 to $5.4^{\circ}$ (colored lines). For each angle, the bias is shown in solid line and the standard deviation in dashed line.

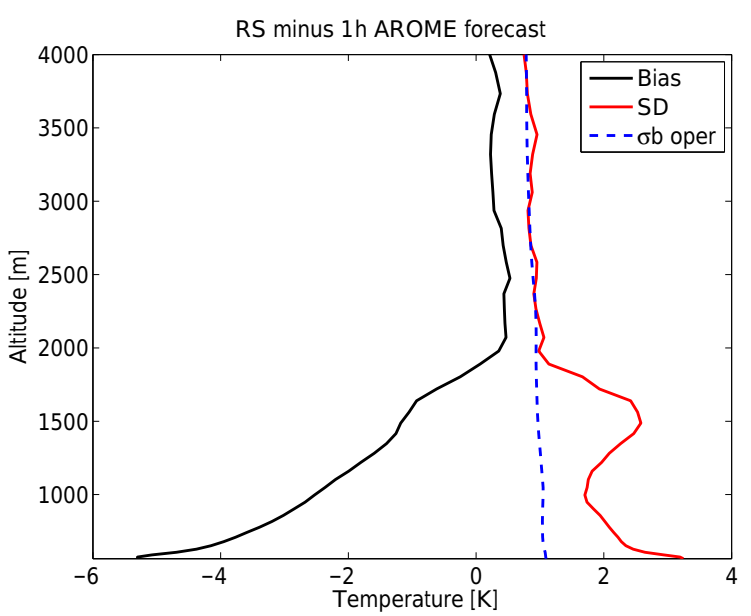

Figure 8. Bias (black line) and standard deviation (red line) of the radiosonde minus $1 \mathrm{~h}$ AROME temperature differences. The operational background error used in AROME for the assimilation of satellite data is shown as the blue dashed line.

text complicated. However, it should affect higher moments of the error distribution than those used in the $\mathbf{B}$ matrix.

\subsection{Sensitivity of retrievals to elevation angles and bias correction}

The 1DVAR method with the settings previously described has been applied to MWR observations during the two IOPs of the Passy-2015 campaign. The retrievals are evaluated against radiosondes and compared to the standard HATPRO linear regressions with the Payerne coefficients. Here the RS profiles are interpolated to the retrieval grid without taking into account the smoothing errors due to the limited vertical resolution of the MWR. In fact, this resolution is approximately between 50 and $500 \mathrm{~m}$ and only four independent pieces of information can be extracted from the signal (Löh- nert and Maier, 2012). In contrast, the temperature profile is sampled approximately every $10 \mathrm{~m}$ by the RS. In the future, the averaging kernel matrix could be used to bring the RS profile onto the MWR vertical resolution. According to Sect. 5, a constant bias correction is removed from all channels before the 1DVAR algorithm. This bias correction is not used for the linear regressions that directly come from the uncorrected BT measurements and the HATPRO proprietary software. Figure 9 evaluates temperature retrievals against radiosondes in terms of bias and RMSE focussing only on clear-sky profiles. For the sake of clarity Fig. 9 also shows MWR retrievals either with regression or 1DVAR with a focus on the range $0-1000 \mathrm{~m}$.

To evaluate the impact of the bias correction, 1DVAR retrievals with and without bias correction are also compared while the impact of low elevation angles is investigated by comparing retrievals using only zenith angle or all angles.

Very similar values of mean deviations are found (from -0.4 to $0.2 \mathrm{~K}$ ) for the two 1DVAR configurations implementing a bias correction (zenith and boundary layer scan) despite a decrease of the bias in the first $100 \mathrm{~m}$ with additional low elevation angles. Regressions show a larger bias with values between -0.1 and $0.8 \mathrm{~K}$. These values are reduced compared to those observed with neural networks in Martinet et al. (2015). Without applying a bias correction to the measurements, a small degradation in the 1DVAR bias is observed below $1000 \mathrm{~m}$. The maximum degradation is found at $1150 \mathrm{~m}$, where the bias reaches $0.7 \mathrm{~K}$ instead of $-0.03 \mathrm{~K}$.

1DVAR RMSE values are smaller than $0.8 \mathrm{~K}$ below $500 \mathrm{~m}$ and within $1 \mathrm{~K}$ through all the atmospheric profile. Large RMSE values are found close to the surface for all retrieval methods (up to $1.6 \mathrm{~K}$ ). The best accuracy of 1DVAR retrievals is found when the bias correction is applied to the measurements and using all elevation angles up to $5.4^{\circ}$. A degradation below $1000 \mathrm{~m}$ in the 1DVAR retrievals is observed when only observations at zenith are used in the min- 
imization. In this case, the RMSE values can reach $1.2 \mathrm{~K}$ instead of $0.8 \mathrm{~K}$ with low elevation angles. This result demonstrates the benefit of low elevation angles to resolve temperature inversions below $1000 \mathrm{~m}$. Below $1000 \mathrm{~m}$, regressions perform slightly better (differences between 0.1 and $0.2 \mathrm{~K}$ in RMSE) than 1DVAR. Above $1000 \mathrm{~m}$ 1DVAR outperforms regressions whose RMSE values increase up to $2.5 \mathrm{~K}$ at $6000 \mathrm{~m}$. Overall, 1DVAR retrievals provide the best estimate of the atmosphere. The performance of 1DVAR retrievals is similar when using the standard deviations from the operational $\mathbf{B}$ matrix and a custom $\mathbf{B}$ matrix computed comparing AROME and RS profiles (not shown). This suggests that the operational B matrix may be safely adopted for other sites where RS profiles are not available for computing a custom B matrix. However, in the future, it would be interesting to investigate the sensitivity of the 1DVAR retrievals to the flow dependency of the $\mathbf{B}$ matrix and particularly to the vertical correlation lengths. The flow dependency and diurnal cycle of forecast errors can be determined by implementing a real-time AROME ensemble assimilation system (Ménétrier et al., 2014). This is under development and should be available in 2018.

In order to investigate the large RMSE values observed close to the surface in more detail, time series of the temperature difference between the surface (external weather station) and the first HATPRO level are investigated in Fig. 10. This difference is compared to the differences between the surface station and tower measurements at $5 \mathrm{~m}$. The evolution of the temperature error is compared to the diurnal cycle of the temperature difference between the surface $(1.5 \mathrm{~m})$ and the RS measurement at the first level above $(\sim 10 \mathrm{~m}$ a.g.1). Positive values indicate stable atmosphere while negative values indicate convective conditions. We note a correlation between the decrease in the stability and the increase in the HATPRO surface error. Maximum differences $(-9 K)$ are found when the stability is minimum, corresponding to a maximum of convective activity during daytime. The MWR seems to significantly underestimate the surface warming during the transition phase from stable to convective conditions. However, MWR retrievals can easily be combined with surface sensors to provide a higher accuracy at the surface. To test the feasibility of combining surface measurements and MWR observations in a physical way, the tower measurement at $5 \mathrm{~m}$ was included in the observation vector with a sharp surfacepeaked weighting function. The 1DVAR retrievals look very similar to what was previously shown but a significant improvement in the RMSE at the surface was found with a decrease from 1.6 to $1 \mathrm{~K}$, as expected (this configuration is used later on in Fig. 13). In the future, this combination could thus be used by deploying a well-calibrated surface station in parallel to the MWR.

\subsection{Sensitivity of retrievals to the a priori}

The previous section has investigated the capability of MWR observations to be assimilated into NWP models by following a similar approach to operational assimilation systems (3DVAR, 4DVAR). However, in the context of field campaigns and the study of boundary layer processes, it can be interesting to get the best possible 1DVAR retrievals by using a more appropriate background profile. In the case of the Passy-2015 field campaign, thanks to the high temporal resolution of RS, the previously launched RS can be used as the background profile instead of the AROME $1 \mathrm{~h}$ forecast to start the minimization from a more reasonable a priori profile. The $\mathbf{B}$ matrix has also been recomputed according to the differences between two successive radiosondes in order to be consistent. In order to evaluate this new configuration Fig. 11 compares the accuracy of 1DVAR retrievals whether either $1 \mathrm{~h}$ AROME forecasts or the previously launched radiosondes are used as backgrounds. As expected when radiosondes are used as backgrounds, the bias is decreased during the analysis, providing the best accuracy compared to the other retrievals. In terms of RMSE, the 1DVAR accuracy is improved between 400 and $1200 \mathrm{~m}$ and outperforms the regressions through all the atmospheric profile except a slight degradation at $1200 \mathrm{~m}$. Using RS as backgrounds, RMSE values are below $0.6 \mathrm{~K}$ in the first $1000 \mathrm{~m}$ and within $1 \mathrm{~K}$ above.

An attempt to use the 1DVAR algorithm in cloudy conditions is also shown in Fig. 11. The liquid water path is estimated from HATPRO with a simple and classical dual channel algorithm using brightness temperature measurement at 23 and $31 \mathrm{GHz}$ (Westwater, 1978). The liquid water content profile is estimated from the background temperature and humidity profiles from a modified adiabatic assumption (Karstens et al., 1994) in the layer where the relative humidity exceeds $95 \%$. The computed liquid water content profile is then scaled with the estimated liquid water path. The obtained liquid water content profile is translated vertically to fit the cloud base height provided by the ceilometer. In case no atmospheric layer exceeds the $95 \%$ relative humidity threshold, a cloud layer is placed at the cloud base height provided by the ceilometer with a geometrical thickness of one layer and a liquid water path equal to the one derived from HATPRO measurements. As MWRs are mostly sensitive to the integrated liquid water content rather than the vertical distribution of clouds, this configuration should be sufficient to take into account the cloud contribution in the radiative transfer. Note that only 25 profiles are taken into account in the statistics, which makes the dataset too small for a good representativeness. A large degradation of the 1DVAR retrievals from AROME forecasts is observed in cloudy conditions with an increase of RMSE values up to $3 \mathrm{~K}$ at $1000 \mathrm{~m}$. Contrary to what one may think, this degradation does not seem to be directly related to large background errors in the liquid water content but more to the misrepresentation of cloud-based 

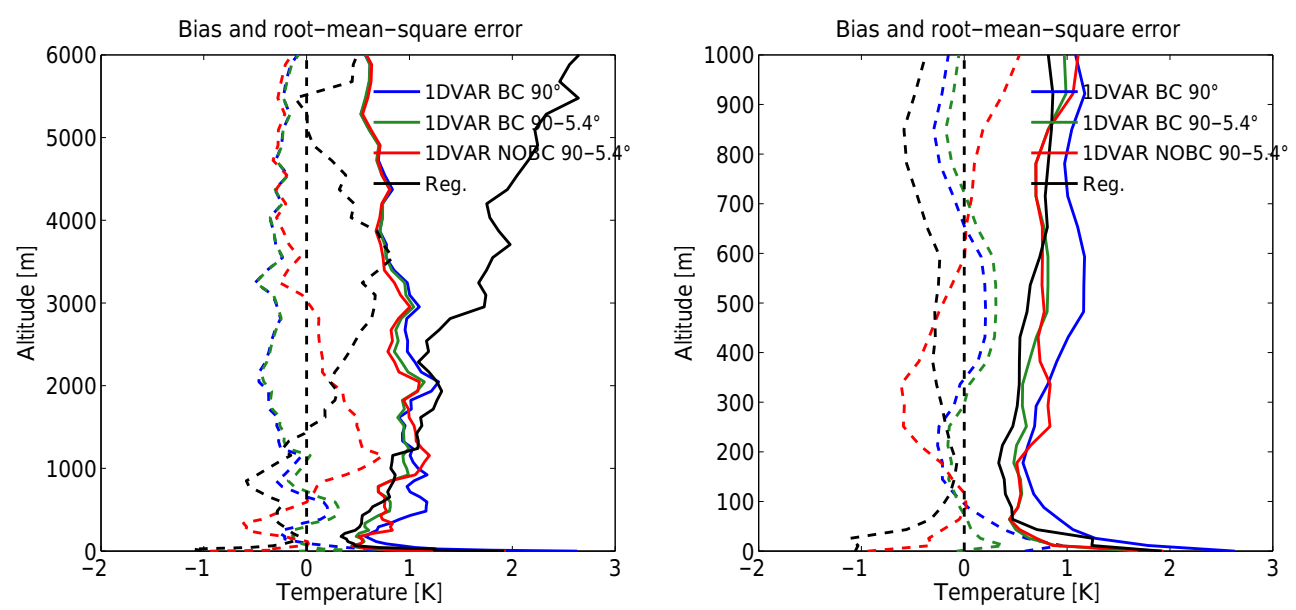

Figure 9. Vertical profiles of bias (dashed lines) and root-mean-square errors (solid lines) of MWR retrievals against radiosondes: 1DVAR retrievals from AROME $1 \mathrm{~h}$ forecasts, all elevation angles and bias correction (green), all elevation angles but no bias correction (red), only zenith angle and bias correction (blue) and linear regressions (black). Results on 56 clear-sky temperature profiles.

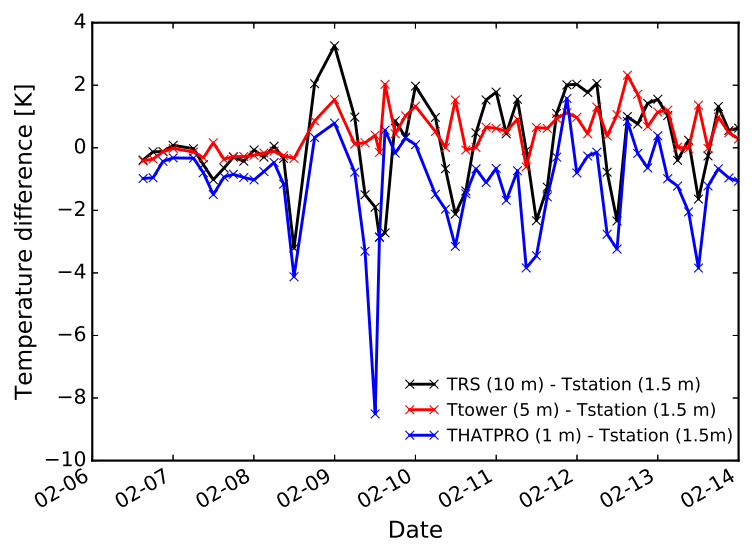

Figure 10. Time series of temperature differences between the first HATPRO level and a surface weather station (blue line), between tower measurements at $5 \mathrm{~m}$ and the surface station (red line). Radiosonde temperature difference (black line) between the surface weather station and the first level above.

temperature inversions in AROME. In fact, Fig. 5 shows that most of the cloudy profiles are located at the beginning of the first IOP between 7 and 9 February. This period corresponds to the strong temperature inversion at $1000 \mathrm{~m}$ altitude missed by AROME (Fig. 4), inducing large forecast errors up to $-9 \mathrm{~K}$. As the information content from the microwave radiometer is maximum below $1000 \mathrm{~m}$ and decreases with altitude, the MWR likely does not bring enough information during the analysis to correct the background profile. In addition to this decrease in information content, the large RMSE value at $1000 \mathrm{~m}$ is likely due to the smoothing error related to the low vertical resolution of MWRs. This is evident in the bias, showing large positive to negative values going from 500 to $1500 \mathrm{~m}$ altitudes.
To confirm that this degradation does not come from large errors in the liquid water content background profile, IDVAR retrievals have been performed using only opaque channels $(54-58 \mathrm{GHz})$. These channels are known to be less affected by cloud liquid water emission contrary to transparent channels. Figure 12 shows the RMSE of 1DVAR retrievals, with this reduced channel set differentiating the results between clear-sky and cloudy-sky conditions. In clear-sky conditions, using only opaque channels, a slight improvement between 900 and $1600 \mathrm{~m}$ and a degradation between 1600 and $3000 \mathrm{~m}$ are observed, although these differences stay small $(0.1 \mathrm{~K}$ in RMSE). In cloudy-sky conditions, the same 1DVAR statistics are found with different channel configurations. As transparent channels are more affected by cloud liquid water emission, we could have expected to observe a larger degradation when these channels are used if the liquid water content is not well modeled. As few differences are observed with transparent channels included in cloudy conditions, the degradation in cloudy conditions is likely to come from sharp elevated temperature inversions.

In cloudy-sky conditions, regressions also show a degradation with a RMSE of $2.2 \mathrm{~K}$ at $1000 \mathrm{~m}$ but are slightly better than 1DVAR below $1300 \mathrm{~m}$ if AROME is used as background (Fig. 11). Above $1300 \mathrm{~m}$, an increase in the bias makes the regressions less accurate than both 1DVAR configurations. The best performance is found if radiosondes are used as backgrounds even though the RMSE values still reach $1.8 \mathrm{~K}$ at $1000 \mathrm{~m}$. This configuration shows that one way to deal with sharp elevated temperature inversion with MWRs could be to use a background profile already simulating this inversion.

In order to evaluate the added value brought by MWRs to the background profile and how much improvement could be expected in future data assimilation, Fig. 13 summarizes the performance of the 1DVAR retrievals either from RS or 
from AROME backgrounds compared to the AROME forecast errors. It also shows the performance of the "persistent" method in which the last RS is used as an estimate of the current conditions. As radiosondes were launched every $3 \mathrm{~h}$ during the Passy-2015 campaign, it is interesting to investigate whether MWRs could still offer information on atmospheric changes during the $3 \mathrm{~h}$ time window. Note that when the previously launched RS is used as background, the external weather station was added to the observation vector.

In clear-sky conditions, as previously mentioned, we observe a large RMSE of the AROME forecasts up to $8 \mathrm{~K}$ due to a positive bias up to $6 \mathrm{~K}$ in the AROME background that decreases with altitude. The RMSE profiles of 1DVAR retrievals indicate that a significant amount of information can be extracted from MWR observations to improve the AROME backgrounds even though large errors below $1500 \mathrm{~m}$ are observed in the a priori profile. This situation is quite extreme as the background is very far from the truth at the beginning of the minimization. However, the largest background errors are found in the $0-1000 \mathrm{~m}$ range where MWRs can best constrain the minimization due to the high information content of the instrument in this altitude range.

In cloudy-sky conditions, AROME suffers from large errors at both surface and $1000 \mathrm{~m}$, corresponding to sharp temperature inversions. A significant improvement of the AROME forecasts is observed in the first $1200 \mathrm{~m}$. Temperature errors are decreased from 3.5 to $0.4 \mathrm{~K}$ at $200 \mathrm{~m}$ and from 4.5 to $2.5 \mathrm{~K}$ at the cloud-based inversion. This result demonstrates the potential benefit of assimilating MWR observations in NWP models in both clear-sky and cloudy-sky conditions.

Even though RS could be launched at a high temporal resolution (here up to $3 \mathrm{~h}$ ), the $10 \mathrm{~min}$ resolution of MWRs can be valuable to fill in the gap between RS. In fact, we note that even if radiosondes are launched every $3 \mathrm{~h}$, significant changes in the boundary layer temperature profiles are observed between two adjacent RS with RMSE values larger than $1 \mathrm{~K}$ below $1000 \mathrm{~m}$ and up to $4.4 \mathrm{~K}$ at the surface in clear-sky conditions. In cloudy-sky conditions, errors up to $1.6 \mathrm{~K}$ in RMSE in the temperature profile are also associated to the cloud-based inversion with this "persistent" method. 1-D assimilation of MWR observations manages to significantly decrease the errors in the boundary layer mainly below $1500 \mathrm{~m}$ with values between 0.3 and $1.3 \mathrm{~K}$ in the first $1000 \mathrm{~m}$. MWR observations can thus fill in the gap between $3 \mathrm{~h}$ radiosondes to provide valuable temperature profiles. This result also demonstrates how the MWR temporal resolution is a necessity to complete our understanding and description of the ABL diurnal cycle.

\subsection{Examples of temperature profiles}

In order to illustrate the capability of MWRs to resolve deep near surface as well as elevated temperature inversions, Fig. 14 shows temperature profiles during two op- posite weather regimes: convective and cloudy conditions on 7 February at 06:04 UTC and stable clear conditions on 13 February at 02:56 UTC. In each figure, temperature retrievals from different configurations (regression, 1DVAR from AROME forecast, 1DVAR from radiosonde) are compared to radiosonde. The a priori profile used in each configuration, either the previously launched radiosonde or the $1 \mathrm{~h}$ AROME forecast, is also shown. First of all, we note the difficulty of ground-based MWRs to resolve high level inversions. Neither the regression nor the AROME 1DVAR can catch the sharp inversions at $1000 \mathrm{~m}$ above ground level. Only the RS 1DVAR is able to catch it because the minimization starts from a background profile already simulating an elevated inversion that is barely modified during the retrieval. Note that 1DVAR with AROME background shows an elevated inversion, though the AROME profile is almost linear. This already represents an improvement with respect to the AROME background, which is much smoother. This limitation is a well-known issue of MWRs; Massaro et al. (2015) suggested the use of additional pressure and temperature observations from meteorological stations on the surrounding mountain slopes. Our study shows that another way of improvement is to use an external information to infer the presence of an elevated temperature inversion that will be incorporated in the background of the 1DVAR algorithm. An improvement can also be expected from more appropriate vertical correlations in the $\mathbf{B}$ matrix. In fact, correlations currently used probably smooth the increments and a reduction on the vertical correlation length should lead to a beneficial impact on the retrievals in such conditions. This approach will be investigated in the future.

Contrary to the high-level inversion, MWRs can catch very well clear-sky deep near-surface temperature inversions as observed during the stable episode of the Passy-2015 campaign. Both 1DVAR and regressions capture the structure of the profile well, even though 1DVAR retrievals are slightly more accurate than regressions. We again note the significant improvement of the AROME profile in the lowest $500 \mathrm{~m}$ thanks to the MWR information content brought during the analysis.

\section{Conclusions}

Within the Passy-2015 field campaign, a HATPRO groundbased microwave radiometer was operated in a deep Alpine valley, making instrumental deployment due to surrounding mountains difficult. A 1DVAR technique combining $1 \mathrm{~h}$ forecasts of the convective scale model AROME and observations from the HATPRO MWR was tested and evaluated during two IOPs, focussing on wintertime stable boundary layers out of 3 months of instrumental deployment. In such complex terrain we could have expected the measurements to be affected by surrounding mountains; one interesting result of this study was that MWR observations are not affected in 
(a) Bias and root-mean-square error (clear)

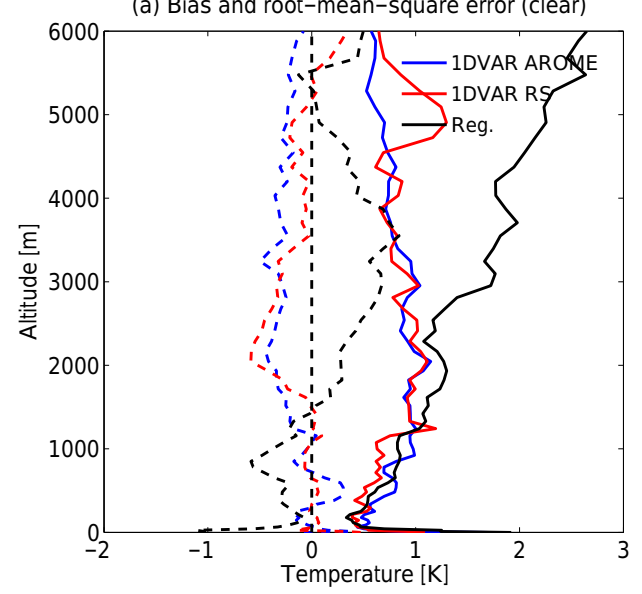

(b) Bias and root-mean-square error (cloudy)

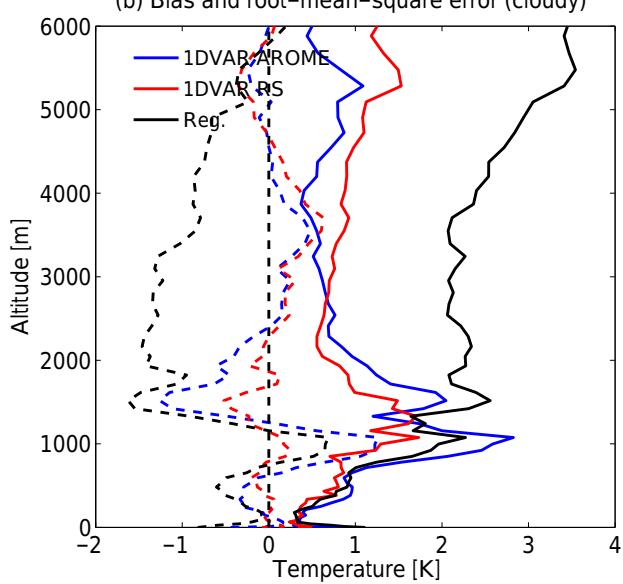

Figure 11. Vertical profiles of bias (dashed lines) and root-mean-square errors (solid line) of 1DVAR retrievals using either AROME $1 \mathrm{~h}$ forecast (blue) or previously launched radiosonde (red) as background. 1DVAR retrievals are performed with bias correction and using all elevation angles $\left(90\right.$ to $\left.5.4^{\circ}\right)$. Comparison with linear regressions (black line). Left panel shows results on 56 clear-sky temperature profiles while right panels shows results on 25 cloudy-sky temperature profiles.

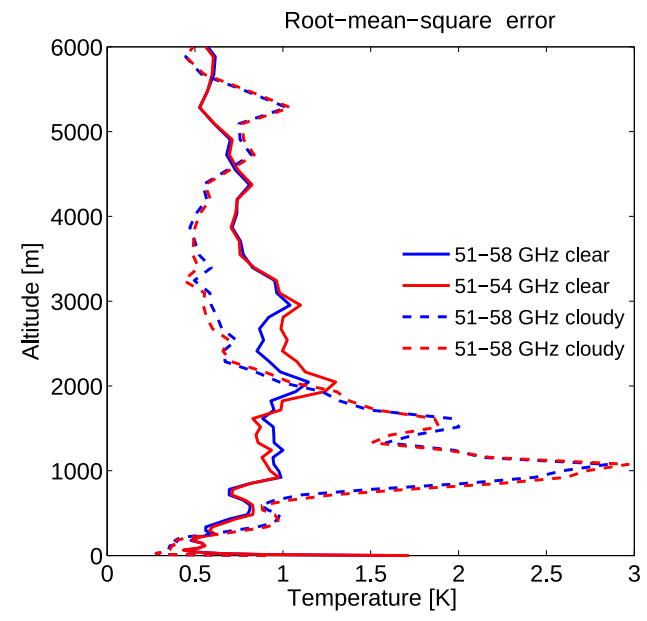

Figure 12. Vertical profiles of root-mean-square errors of 1DVAR retrievals using AROME $1 \mathrm{~h}$ forecasts as backgrounds. Either all V-band channels (blue) or only opaque channels (red) are used. Results are differentiated by clear-sky (solid lines) or cloudy-sky conditions (dashed lines)

such a narrow valley, even going down to $5^{\circ}$ elevation angles. Previous papers deploying MWRs in complex terrain are not abundant; among them we can cite Kneifel et al. (2009), Kneifel et al. (2010), Cimini et al. (2011); Xie et al. (2012) and Massaro et al. (2015). In Kneifel et al. (2009) the terrain is not as complex as in Passy, with a maximum elevation of only $350 \mathrm{~m}$, and only integrated water vapor retrievals are investigated. Neither Kneifel et al. (2009) nor Xie et al. (2012) investigate temperature profile retrievals and the radiometer is deployed at $2650 \mathrm{~m}$ above sea level, which differs from the deployment at the bottom of the $2000 \mathrm{~m}$ deep Passy valley.
In Cimini et al. (2011), the terrain is more complex but the IDVAR is investigated with a global NWP model at a $10 \mathrm{~km}$ horizontal resolution and using only one elevation angle in addition to the zenith. The radiometer measurements do not go lower than an elevation angle of $15^{\circ}$, which significantly limits the possible perturbation from surrounding mountains. Massaro et al. (2015) deploy the instrument in a valley with a free viewing angle up to $28 \mathrm{~km}$ and only focus on regressions. Regarding the Passy valley, the free line of sight is limited to $5 \mathrm{~km}$ in the Passy direction and 1DVAR retrievals from a convective scale model are performed. Temperature gradients were also larger compared to those observed in Massaro et al. (2015).

An evaluation of the accuracy of the AROME model was first studied. A large underestimation of the surface cooling up to $-12 \mathrm{~K}$ during the most stable episode was observed. This is a well-known issue of current NWP models that motivated, among other scientific questions, the preparation of the Passy-2015 campaign. This issue is currently investigated by the modeling community at CNRM and some significant leads for improvement have already been found. During the beginning of the IOP, AROME was found to smooth cloudbased inversions, leading to larger errors at the cloud base around $1000 \mathrm{~m}$, while during clear-sky conditions the temperature inversion is not large enough. The measured BT measurements were compared with those simulated either from AROME $1 \mathrm{~h}$ forecasts or RS and the ARTS2 radiative transfer model. The goal of this monitoring is to propose a bias correction to improve the retrieval of atmospheric profiles. The use of the AROME model to compute the instrumental bias correction was found to be inappropriate because the BT deviations for opaque channels are mainly driven by the large forecast errors in the boundary layer during sta- 

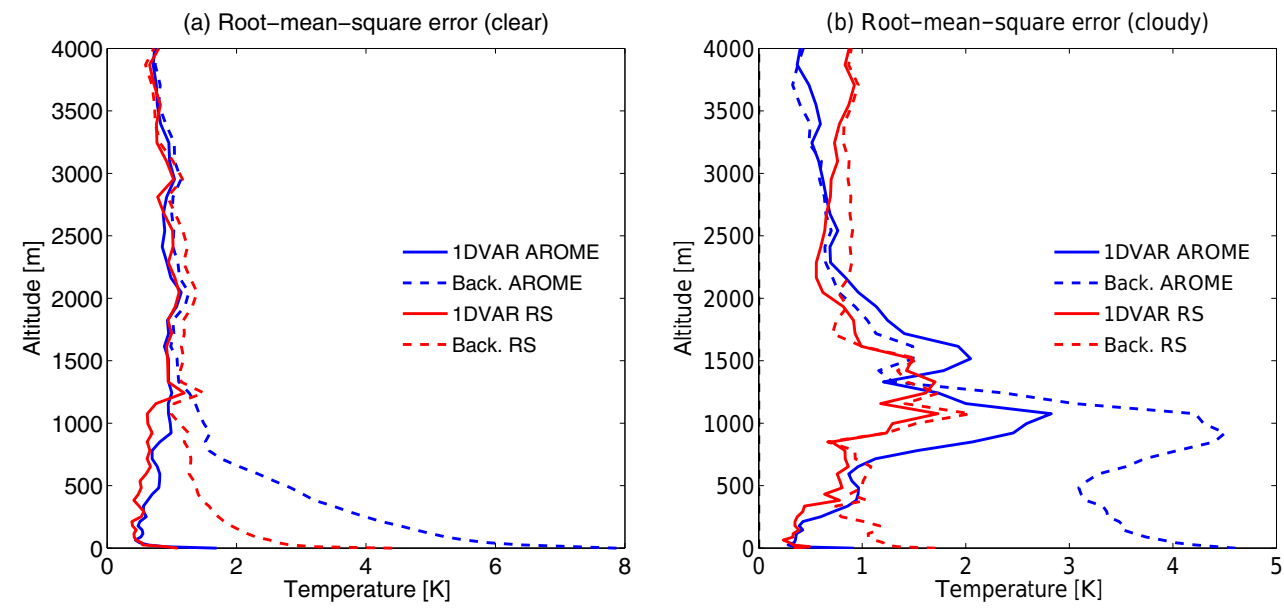

Figure 13. Vertical of profiles root-mean-square errors of 1DVAR retrievals using the previously launched radiosonde (red line) or the AROME forecasts (blue line) as backgrounds. Comparison with the persistent method where the last RS is used as an estimate of the current conditions (dashed red) and the AROME forecast errors (dashed blue). Here, the weather station is included in the 1DVAR from RS to improve the temperature retrieval at the surface $(1.5 \mathrm{~m})$. Statistics on 56 clear-sky profiles (a) and 25 cloudy-sky profiles (b).
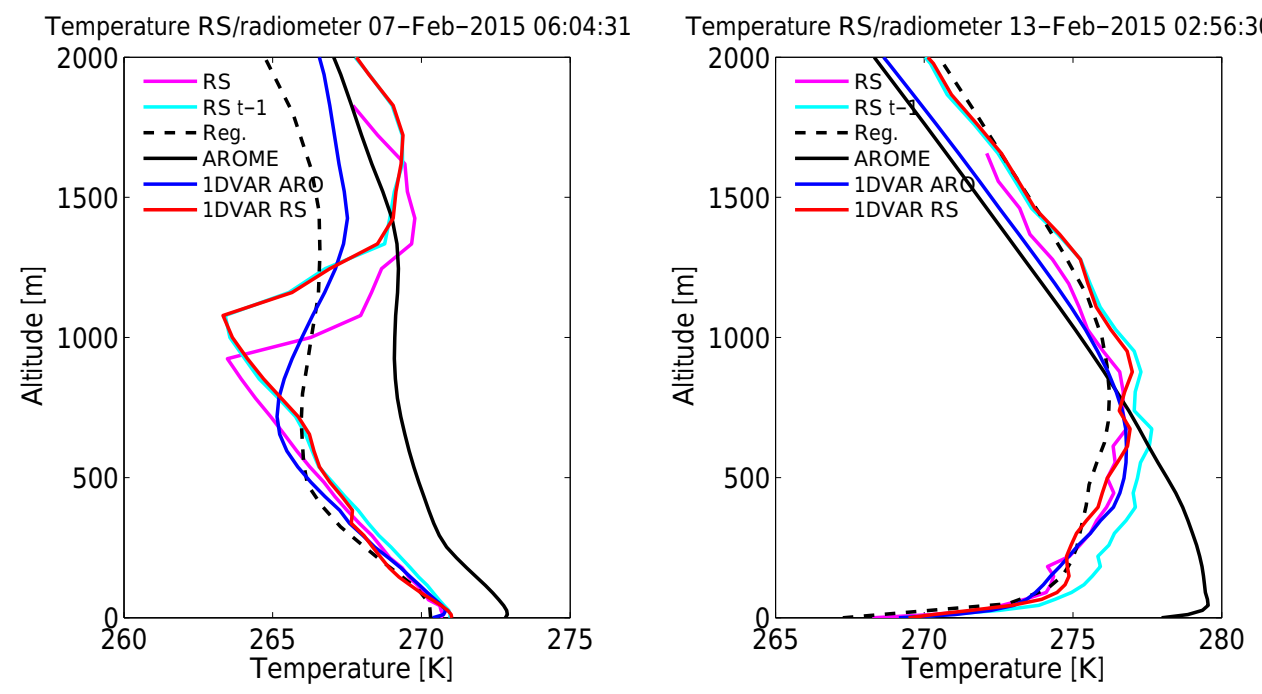

Figure 14. Vertical profiles of temperature during convective conditions (7 February 2015 at 06:04 UTC, top panel) or stable conditions (13 February at 02:56 UTC). Comparison between radiosonde profile (magenta), linear regression (dashed black line) and 1DVAR from AROME forecasts (blue), 1DVAR from previous radiosonde (red). Background profiles corresponding to either the $1 \mathrm{~h}$ AROME forecast (black) or the previously launched radiosonde (cyan) are also shown.

ble conditions. The instrumental bias was thus inferred from BT simulations with the RS launched during the campaign in clear-sky conditions. A large negative bias was observed for the most transparent channels with values up to $-4.2 \mathrm{~K}$ $\left(52.28 \mathrm{GHz}, 90^{\circ}\right)$, while the bias was below $0.5 \mathrm{~K}$ for opaque channels and all elevation angles. Relatively low standard deviations (within $1 \mathrm{~K}$ ) were observed for channels and elevation angles used in the retrieval, demonstrating that the biases can be safely removed by applying a constant bias correction. The bias is close to that found in previous studies. This demonstrates that the bias can be assumed constant as long as calibrations are performed properly. The second part of this study evaluated 1DVAR retrievals in terms of bias and RMSE against collocated radiosondes. By exploiting the 1DVAR assimilation of MWR observations, the large forecast errors close to the surface (up to $8 \mathrm{~K}$ in RMSE) were decreased within $1 \mathrm{~K}$ through all atmospheric profiles except the surface temperature (1.6 K RMSE). This result is encouraging because it shows the high information content of MWRs in the boundary layer, specifically where the AROME forecasts are less accurate and could be improved by a dense network of ground-based instruments. 1DVAR re- 
trievals were found to outperform linear regressions above $1000 \mathrm{~m}$, where RMSE values increase up to $2.5 \mathrm{~K}$ at $6000 \mathrm{~m}$. Linear regressions show similar performance below $1000 \mathrm{~m}$. The use of the elevation scanning mode was also found to significantly improve the retrievals below $1000 \mathrm{~m}$ while the use of a bias correction improves the retrievals below $2000 \mathrm{~m}$. These last results are not in agreement with the results in Martinet et al. (2015). However, the dataset used in this study contains mainly deep clear-sky near-surface temperature inversions for which low elevation angles can bring new information to the zenith mode. Finally, the use of an external weather station to constrain the temperature retrieval at the surface can decrease the RMSE values from 1.6 to $1 \mathrm{~K}$, which includes the uncertainty due to relative distance.

In order to improve 1DVAR retrievals for processes in the context of field campaigns, RS previously launched during the field campaign can be used as backgrounds in place of AROME forecasts. Starting from an a priori profile already closer to the true atmospheric state, a better estimation of the optimal atmospheric profile should be observed. In clearsky conditions, this configuration leads to an improvement of IDVAR retrievals below $1000 \mathrm{~m}$ with RMSE values below $0.6 \mathrm{~K}$. An attempt to retrieve temperature profiles in cloudy conditions was also studied. A significant degradation of both regressions and 1DVAR was found, in particular around $1000 \mathrm{~m}$ with RMSE values around $2 \mathrm{~K}$ for regressions and $3 \mathrm{~K}$ for $1 \mathrm{DVAR}$ retrievals. This degradation is significantly reduced when RS are used as backgrounds. This degradation at $1000 \mathrm{~m}$ is probably due to cloud-based temperature inversions not caught by the MWR and does not seem to be directly related to large background errors in the liquid water absorption. This study confirms the known difficulty of MWRs to capture elevated temperature inversions in cloudy-sky conditions at the level of the valley crest (Crewell and Lohnert, 2007; Massaro et al., 2015) while highlighting the high capability of MWRs to catch clear-sky deep nearsurface temperature inversions during stable boundary layers. MWR observations were also found to provide valuable information between two adjacent RS to catch significant changes in the ABL temperature profile.

Regarding the scientific questions addressed in Sect. 1, our results show that MWRs are expected to bring valuable information into NWP models up to $3 \mathrm{~km}$ altitude but mainly in the first kilometers in both clear-sky and cloudy-sky conditions. With an accuracy between 0.5 and $1 \mathrm{~K}$ RMSE, our study has proven MWRs to be capable of resolving deep near-surface temperature inversions observed in complex terrain during stable boundary layer conditions. This accuracy can be obtained only if the MWR's field of view is free of obstacles and is similar to what was observed in less complex terrain. Elevated temperature inversions are still challenging due to the decreased vertical resolution of the instrument with altitude. Using a more appropriate background, simulating an elevated inversion was found to greatly improve the retrievals. In the future, extra work needs to be under- taken to decrease the correlation length of the backgrounderror-covariance matrix, which should improve the retrievals. A new generation of MWRs also shows a larger sensitivity which is expected to help resolve elevated inversions. Finally, synergy with other passive and active instruments (infrared radiometers and lidars) is expected to improve the vertical resolution of the retrievals through all atmospheric columns (Barrera-Verdejo et al., 2016).

The results shown in this study are encouraging and demonstrate the potential for assimilating MWRs in operational convective scale models even though studies on larger datasets and longer time periods should be done. The development of the ground-based version of the fast radiative transfer model RTTOV (RTTOV-gb; De Angelis et al., 2016) paves the way for future data assimilation of brightness temperature measurements, which should bring more in the assimilation system than retrievals (Caumont et al., 2016). In the context of urbanized valley, this study has proven the capability of MWRs for long-term monitoring to improve our understanding of wintertime pollution events. Temperature gradients linked to the atmospheric stability could be used to better forecast wintertime pollution events. Scanning in two different directions of the valley, MWR observations also offer the possibility of investigating temperature heterogeneity in the valley and how these differences are linked to the mesoscale circulation. This will be further investigated in a future study.

In the future, 1DVAR retrievals will be extended to humidity and liquid water content. Improvement in the definition of the $\mathbf{R}$ and $\mathbf{B}$ matrices will also be carried out to be optimized with the weather regime.

Data availability. Data used in this paper are available on the Passy-2015 campaign website: http://passy.sedoo.fr.

Competing interests. The authors declare that they have no conflict of interest.

Acknowledgements. We thank Alexander Haefele from $\mathrm{Me}$ teoSwiss for kindly providing us with the Payerne coefficient files used in the microwave radiometer retrievals. All the members of the CNRM/GMEI/LISA team are thanked for the maintenance and deployment of the MWR during field campaigns. The Passy-2015 field campaign was supported by ADEME through the French national programme LEFE/INSU and by METEO-FRANCE. We thank the cities of Passy and Sallanches for their kind support. The field experiment was led by CNRM while LEGI is the principal investigator of the LEFE/INSU project. Data are managed by SEDOO at Observatoire Midi-Pyrénées. This article is based upon work from COST Action ES1303 (TOPROF), supported by COST (European Cooperation in Science and Technology) www.cost.eu. We acknowledge the helpful comments from two anonymous reviewers to improve the manuscript. 
Edited by: Laura Bianco

Reviewed by: two anonymous referees

\section{References}

Barrera-Verdejo, M., Crewell, S., Löhnert, U., Orlandi, E., and Di Girolamo, P.: Ground-based lidar and microwave radiometry synergy for high vertical resolution absolute humidity profiling, Atmos. Meas. Tech., 9, 4013-4028, https://doi.org/10.5194/amt9-4013-2016, 2016.

Berre, L., Pannekoucke, O., Desroziers, G., Stefanescu, S., Chapnik, B., and Raynaud, L.: A variational assimilation ensemble and the spatial filtering of its error covariances: increase of sample size by local spatial averaging, in: Proc. ECMWF Workshop on Flow-Dependent Aspects of Data Assimilation, 151168, 2007.

Beyrich, F.: Mixing height estimation from sodar data - a critical discussion, Atmos. Environ., 31, 3941-3953, 1997.

Brousseau, P., Berre, L., Bouttier, F., and Desroziers, G.: Background-error covariances for a convective-scale dataassimilation system: AROME-France 3D-Var, Q. J. Roy. Meteor. Soc., 137, 409-422, 2011.

Brousseau, P., Seity, Y., Ricard, D., and Léger, J.: Improvement of the forecast of convective activity from the AROMEFrance system, Q. J. Roy. Meteor. Soc., 142, 2231-2243, https://doi.org/10.1002/qj.2822, 2016

Caumont, O., Cimini, D., Löhnert, U., Alados-Arboledas, L., Bleisch, R., Buffa, F., Ferrario, M. E., Haefele, A., Huet, T., Madonna, F., and Pace, G.: Assimilation of humidity and temperature observations retrieved from ground-based microwave radiometers into a convective-scale NWP model, Q. J. Roy. Meteor. Soc., 142, 2692-2704, 2016.

Chemel, C., Arduini, G., Staquet, C., Largeron, Y., Legain, D., Tzanos, D., and Paci, A.: Valley heat deficit as a bulk measure of wintertime particulate air pollution in the Arve River Valley, Atmos. Environ., 128, 208-215, 2016.

Cimini, D., Hewison, T. J., Martin, L., Güldner, J., Gaffard, C., and Marzano, F. S.: Temperature and humidity profile retrievals from ground-based microwave radiometers during TUC, Meteorol. Z., $15,45-56,2006$.

Cimini, D., Westwater, E. R., and Gasiewski, A. J.: Temperature and humidity profiling in the Arctic using ground-based millimeterwave radiometry and 1DVAR, IEEE T. Geosci. Remote, 48, 1381-1388, 2010.

Cimini, D., Campos, E., Ware, R., Albers, S., Giuliani, G., Oreamuno, J., Joe, P., Koch, S. E., Cober, S., and Westwater, E.: Thermodynamic atmospheric profiling during the 2010 Winter Olympics using ground-based microwave radiometry, IEEE T. Geosci. Remote, 49, 4959-4969, 2011.

Crewell, S. and Lohnert, U.: Accuracy of boundary layer temperature profiles retrieved with multifrequency multiangle microwave radiometry, IEEE T. Geosci. Remote, 45, 2195-2201, 2007.

De Angelis, F., Cimini, D., Hocking, J., Martinet, P., and Kneifel, S.: RTTOV-gb - adapting the fast radiative transfer model RTTOV for the assimilation of ground-based microwave radiometer observations, Geosci. Model Dev., 9, 2721-2739, https://doi.org/10.5194/gmd-9-2721-2016, 2016.
De Angelis, F., Cimini, D., Löhnert, U., Caumont, O., Haefele, A., Pospichal, B., Martinet, P., Navas-Guzmán, F., Klein-Baltink, H., Dupont, J.-C., and Hocking, J.: Long term Observations minus Background monitoring of ground-based microwave radiometer network. Part 1: Brightness Temperatures, Atmos. Meas. Tech. Discuss., https://doi.org/10.5194/amt-2017-112, in review, 2017.

De Franceschi, M. and Zardi, D.: Study of wintertime high pollution episodes during the Brenner-South ALPNAP measurement campaign, Meteorol. Atmos. Phys., 103, 237-250, 2009.

Ebell, K., Löhnert, U., Päschke, E., Orlandi, E., Schween, J. H., and Crewell, S.: A 1-D variational retrieval of temperature, humidity, and liquid cloud properties: Performance under idealized and real conditions, J. Geophys. Res.-Atmos., 122, 1746-1766, https://doi.org/10.1002/2016JD025945, 2017.

Eriksson, P., Jiménez, C., and Buehler, S. A.: Qpack, a general tool for instrument simulation and retrieval work, J. Quant. Spectrosc. Ra., 91, 47-64, 2005.

Eriksson, P., Buehler, S., Davis, C., Emde, C., and Lemke, O.: ARTS, the atmospheric radiative transfer simulator, version 2, J. Quant. Spectrosc. Ra., 112, 1551-1558, 2011.

Gohm, A., Harnisch, F., Vergeiner, J., Obleitner, F., Schnitzhofer, R., Hansel, A., Fix, A., Neininger, B., Emeis, S., and Schäfer, K.: Air pollution transport in an Alpine valley: Results from airborne and ground-based observations, Bound.-Lay. Meteorol., 131, 441-463, 2009.

Güldner, J.: A model-based approach to adjust microwave observations for operational applications: results of a campaign at $\mathrm{Mu}-$ nich Airport in winter 2011/2012, Atmos. Meas. Tech., 6, 28792891, https://doi.org/10.5194/amt-6-2879-2013, 2013.

Hewison, T. J.: Profiling Temperature and Humidity by GroundBased Microwave Radiometers, $\mathrm{PhD}$ thesis, University of Reading, 2006.

Hewison, T. J.: 1D-VAR retrieval of temperature and humidity profiles from a ground-based microwave radiometer, IEEE $\mathrm{T}$. Geosci. Remote, 45, 2163-2168, 2007.

Karstens, U., Simmer, C., and Ruprecht, E.: Remote sensing of cloud liquid water, Meteorol. Atmos. Phys., 54, 157-171, 1994.

Kneifel, S., Crewell, S., Lohnert, U., and Schween, J.: Investigating water vapor variability by ground-based microwave radiometry: Evaluation using airborne observations, IEEE Geosci. Remote S., 6, 157-161, 2009.

Kneifel, S., Löhnert, U., Battaglia, A., Crewell, S., and Siebler, D.: Snow scattering signals in ground-based passive microwave radiometer measurements, J. Geophys. Res.-Atmos., 115, D16214, https://doi.org/10.1029/2010JD013856, 2010.

Küchler, N., Turner, D., Löhnert, U., and Crewell, S.: Calibrating ground-based microwave radiometers: Uncertainty and drifts, Radio Sci., 51, 311-327, 2016.

Lafore, J. P., Stein, J., Asencio, N., Bougeault, P., Ducrocq, V., Duron, J., Fischer, C., Héreil, P., Mascart, P., Masson, V., Pinty, J. P., Redelsperger, J. L., Richard, E., and Vilà-Guerau de Arellano, J.: The Meso-NH atmospheric simulation system. Part I: Adiabatic formulation and control simulations, in: Annales Geophysicae, 16, 90-109, Springer, 1997.

Legain, D., Bousquet, O., Douffet, T., Tzanos, D., Moulin, E., Barrie, J., and Renard, J.-B.: High-frequency boundary layer profiling with reusable radiosondes, Atmos. Meas. Tech., 6, 21952205, https://doi.org/10.5194/amt-6-2195-2013, 2013. 
Legrand, R., Michel, Y., and Montmerle, T.: Diagnosing non-Gaussianity of forecast and analysis errors in a convective-scale model, Nonlin. Processes Geophys., 23, 1-12, https://doi.org/10.5194/npg-23-1-2016, 2016.

Lehner, M. and Gohm, A.: Idealised simulations of daytime pollution transport in a steep valley and its sensitivity to thermal stratification and surface albedo, Bound.-Lay. Meteorol., 134, 327$351,2010$.

Liebe, H., Hufford, G., and Cotton, M.: Propagation modeling of moist air and suspended water/ice particles at frequencies below $1000 \mathrm{GHz}$, in: In AGARD, Atmospheric Propagation Effects Through Natural and Man-Made Obscurants for Visible to MMWave Radiation 11 p (SEE N94-30495 08-32), 1993.

Löhnert, U. and Maier, O.: Operational profiling of temperature using ground-based microwave radiometry at Payerne: prospects and challenges, Atmos. Meas. Tech., 5, 1121-1134, https://doi.org/10.5194/amt-5-1121-2012, 2012.

Löhnert, U., Crewell, S., and Simmer, C.: An integrated approach toward retrieving physically consistent profiles of temperature, humidity, and cloud liquid water, J. Appl. Meteorol., 43, 12951307, 2004.

Löhnert, U., Crewell, S., Krasnov, O., O’Connor, E., and Russchenberg, H.: Advances in continuously profiling the thermodynamic state of the boundary layer: Integration of measurements and methods, J. Atmos. Ocean. Technol., 25, 1251-1266, 2008.

Mahfouf, J.-F., Ahmed, F., Moll, P., and Teferle, F. N.: Assimilation of zenith total delays in the AROME France convective scale model: a recent assessment, Tellus A, 67, 26106, https://doi.org/10.3402/tellusa.v67.26106, 2015.

Martinet, P., Dabas, A., Donier, J. M., Douffet, T., Garrouste, O., and Guillot, R.: 1D-Var temperature retrievals from microwave radiometer and convective scale model, Tellus A, 67, 27925, https://doi.org/10.3402/tellusa.v67.27925, 2015.

Massaro, G., Stiperski, I., Pospichal, B., and Rotach, M. W.: Accuracy of retrieving temperature and humidity profiles by groundbased microwave radiometry in truly complex terrain, Atmos. Meas. Tech., 8, 3355-3367, https://doi.org/10.5194/amt-8-33552015, 2015.

Ménétrier, B., Montmerle, T., Berre, L., and Michel, Y.: Estimation and diagnosis of heterogeneous flow-dependent backgrounderror covariances at the convective scale using either large or small ensembles, Q. J. Roy. Meteor. Soc., 140, 2050-2061, 2014.

Montmerle, T. and Faccani, C.: Mesoscale assimilation of radial velocities from Doppler radars in a preoperational framework, Mon. Weather Rev., 137, 1939-1953, 2009.

National Research Council United States: Research and Researchto-Operations Activities, When Weather Matters: Science and Service to Meet Critical Societal Needs, available at: https://www.nap.edu/catalog/12888/ (last access: 13 September 2017), 2010.

Navas-Guzmán, F., Kämpfer, N., and Haefele, A.: Validation of brightness and physical temperature from two scanning microwave radiometers in the $60 ? \mathrm{GHz} \mathrm{O} 2$ band using radiosonde measurements, Atmos. Meas. Tech., 9, 4587-4600, https://doi.org/10.5194/amt-9-4587-2016, 2016.
Paci, A., Staquet, C., Allard, J., Barral, H., Canut, G., Cohard, J.-M., Jaffrezo, J.-L., Martinet, P., Sabatier, T., Troude, F., Arduini, G., Burnet, F., Brun, C., Chemel, C., Dabas, A., Donier, J.-M., Garrouste, O., Guillot, R., Largeron, Y., Legain, D., Maurel, W., Tzanos, D., Barrau, S., Barret, M., Barrie, J., Belleudy, A., Bouhours, G., Bourrianne, T., Chevrier, F., Douffet, T., Etcheberry, J.-M., Gustave, L., Mazoyer, M., Mercier, S., Moulin, E., Pellan, Y., Piguet, B., Rodier, Q., and Zin, I.: The Passy-2015 field experiment: atmospheric dynamics and air quality in the Arve River Valley, Pollution Atmosphérique, 271, https://doi.org/10.4267/pollution-atmospherique.5903, 2016.

Pergaud, J., Masson, V., Malardel, S., and Couvreux, F.: A parameterization of dry thermals and shallow cumuli for mesoscale numerical weather prediction, Bound.-Lay. Meteorol., 132, 83106, 2009.

Pinty, J. and Jabouille, P.: A mixed-phase cloud parameterization for use in mesoscale non-hydrostatic model: simulations of a squall line and of orographic precipitations, in: Conf. on Cloud Physics, Amer. Meteor. Soc Everett, WA, 217-220, 1998.

Rodgers, C. D.: Inverse methods for atmospheric sounding: theory and practice, vol. 2, World scientific, 2000.

Rose, T., Crewell, S., Löhnert, U., and Simmer, C.: A network suitable microwave radiometer for operational monitoring of the cloudy atmosphere, Atmos. Res., 75, 183-200, 2005.

Rosenkranz, P. W.: Water vapor microwave continuum absorption: A comparison of measurements and models, Radio Sci., 33, 919928, 1998.

Rotach, M. W. and Zardi, D.: On the boundary-layer structure over highly complex terrain: Key findings from MAP, Q. J. Roy. Meteor. Soc., 133, 937-948, 2007.

Seity, Y., Brousseau, P., Malardel, S., Hello, G., Bénard, P., Bouttier, F., Lac, C., and Masson, V.: The AROME-France convectivescale operational model, Mon. Weather Rev., 139, 976-991, 2011.

Silcox, G. D., Kelly, K. E., Crosman, E. T., Whiteman, C. D., and Allen, B. L.: Wintertime PM 2.5 concentrations during persistent, multi-day cold-air pools in a mountain valley, Atmos. Environ., 46, 17-24, 2012.

Stull, R. B.: An introduction to boundary layer meteorology, Springer Science \& Business Media, 13, 2012.

Sullivan, P. P., Moeng, C.-H., Stevens, B., Lenschow, D. H., and Mayor, S. D.: Structure of the entrainment zone capping the convective atmospheric boundary layer, J. Atmos. Sci., 55, 30423064, 1998.

Wattrelot, E., Caumont, O., and Mahfouf, J.-F.: Operational implementation of the 1D+3D-Var assimilation method of radar reflectivity data in the AROME model, Mon. Weather Rev., 142, 1852-1873, 2014.

Westwater, E. R.: The accuracy of water vapor and cloud liquid determination by dual-frequency ground-based microwave radiometry, Radio Sci., 13, 677-685, 1978.

Xie, X., Löhnert, U., Kneifel, S., and Crewell, S.: Snow particle orientation observed by ground-based microwave radiometry, J. Geophys. Res.-Atmos., 117, D02206, https://doi.org/10.1029/2011JD016369, 2012. 